\title{
IAEA Coordinated Research Project on HTGR Physics, Thermal-Hydraulics, and Depletion Uncertainty Analysis
}

Prismatic HTGR Benchmark Specification: Phase II

G. Strydom

April 2018
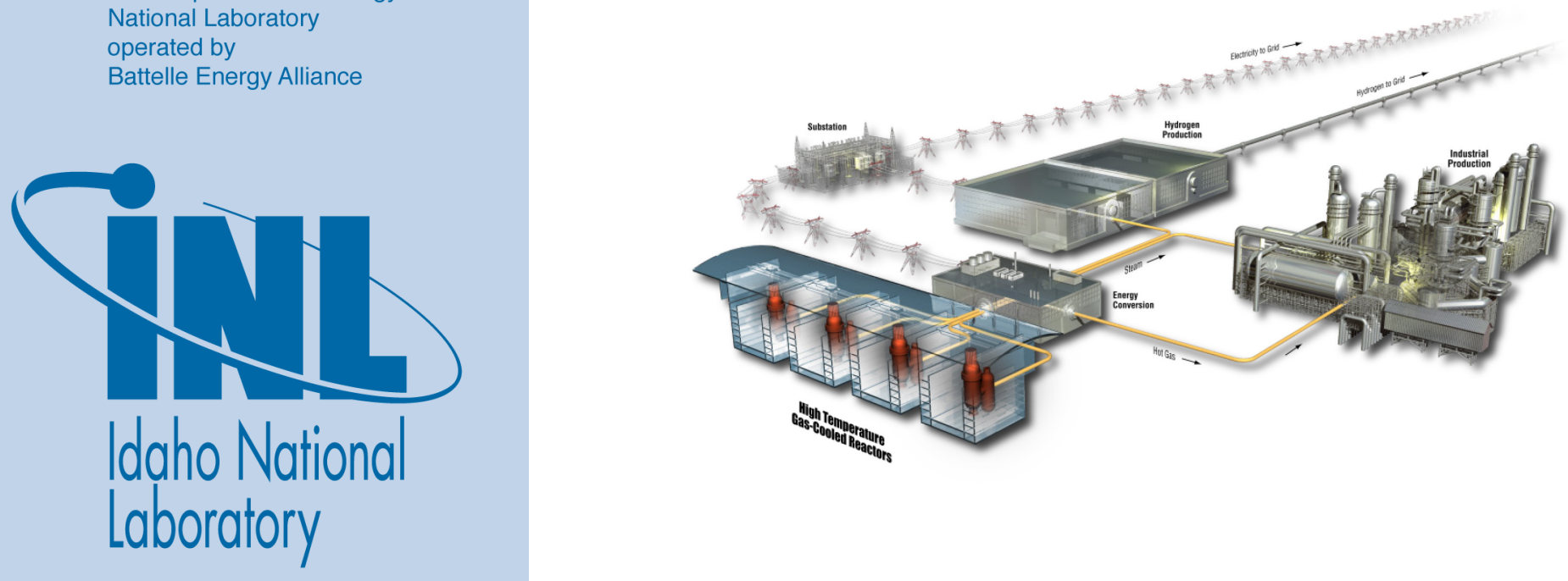


\section{DISCLAIMER}

This information was prepared as an account of work sponsored by an agency of the U.S. Government. Neither the U.S. Government nor any agency thereof, nor any of their employees, makes any warranty, expressed or implied, or assumes any legal liability or responsibility for the accuracy, completeness, or usefulness, of any information, apparatus, product, or process disclosed, or represents that its use would not infringe privately owned rights. References herein to any specific commercial product, process, or service by trade name, trade mark, manufacturer, or otherwise, does not necessarily constitute or imply its endorsement, recommendation, or favoring by the U.S. Government or any agency thereof. The views and opinions of authors expressed herein do not necessarily state or reflect those of the U.S. Government or any agency thereof. 
INL/EXT-18-44815

Revision 0

\title{
IAEA Coordinated Research Project on HTGR Physics, Thermal-Hydraulics, and Depletion Uncertainty Analysis
}

\section{Prismatic HTGR Benchmark Specification: Phase II}

\author{
G. Strydom
}

April 2018

\begin{abstract}
Idaho National Laboratory
INL ART TDO Program

Idaho Falls, Idaho 83415
\end{abstract}

\section{http://www.inl.gov}

Prepared for the

U.S. Department of Energy

Office of Nuclear Energy

Under DOE Idaho Operations Office

Contract DE-AC07-05ID14517 

INL ART TDO Program

\title{
IAEA Coordinated Research Project on HTGR Physics, Thermal-Hydraulics, and Depletion Uncertainty Analysis
}

\section{Prismatic HTGR Benchmark Specification: Phase II}

\author{
INL/EXT-18-44815
}

Revision 0

Author:

Gerhard Strydom

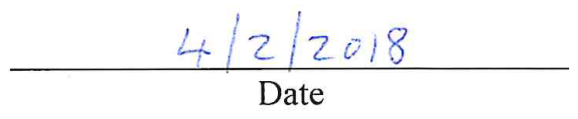

Principle Scientist: Nuclear Science and Technology

Approved by:
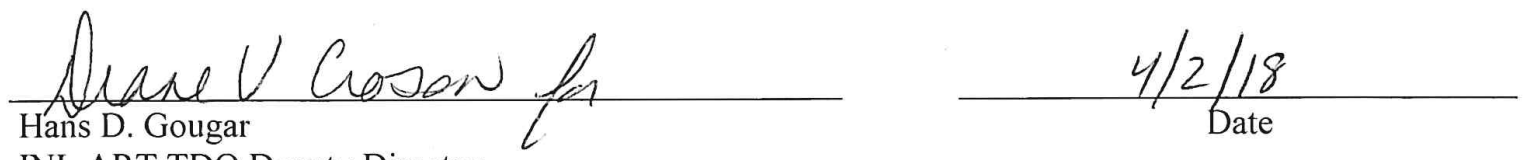

INL ART TDO Deputy Director

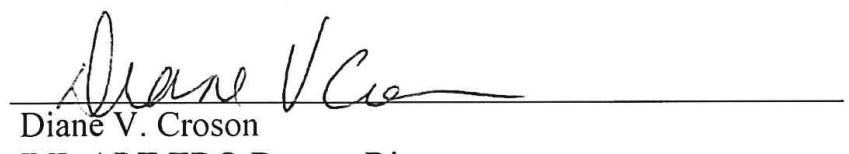

INL ART TDO Deputy Director
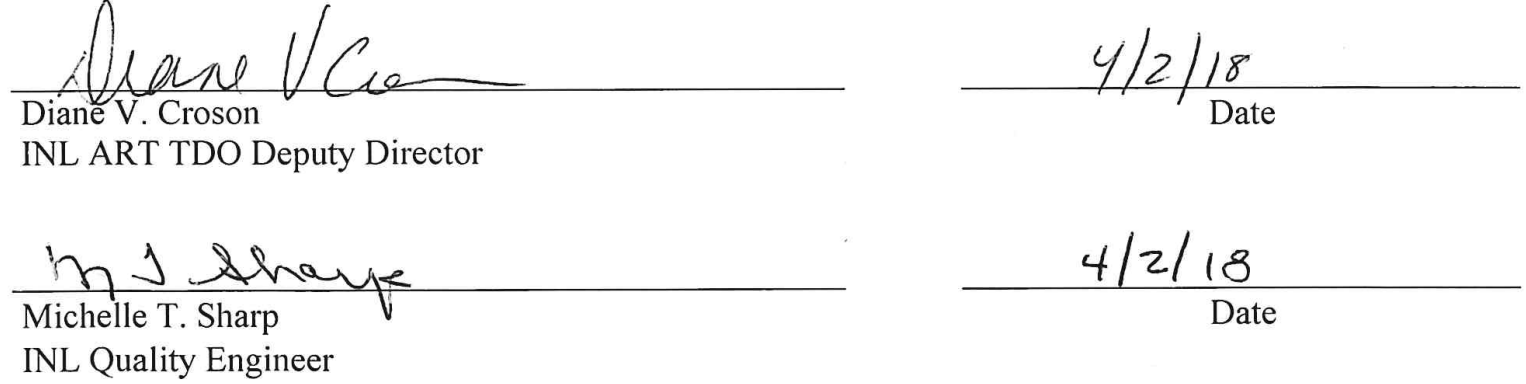

INL Quality Engineer 



\section{CONTRIBUTORS}

\begin{tabular}{|c|c|c|c|}
\hline Name & Organization & Country & Role \\
\hline Victor Boyarinov & $\begin{array}{l}\text { National Research Centre } \\
\text { Kurchatov Institute }\end{array}$ & Russia & Technical Reviewer \\
\hline Tae Young Han & $\begin{array}{l}\text { Korea Atomic Energy } \\
\text { Research Institute }\end{array}$ & South Korea & Technical Reviewer \\
\hline Alexander Grol & $\begin{array}{l}\text { National Research Centre } \\
\text { Kurchatov Institute }\end{array}$ & Russia & Technical Reviewer \\
\hline Kostadin Ivanov & Pennsylvania State University & U.S.A. & $\begin{array}{l}\text { IAEA Coordinated Research } \\
\text { Project (CRP) on HTGR } \\
\text { Uncertainty Analysis in Modeling } \\
\text { (UAM) Coordinator }\end{array}$ \\
\hline Frederik Reitsma & $\begin{array}{l}\text { International Atomic Energy } \\
\text { Agency (IAEA) }\end{array}$ & Austria & IAEA CRP Facilitator \\
\hline Gerhard Strydom & Idaho National Laboratory & U.S.A. & $\begin{array}{l}\text { IAEA CRP Prismatic Reactors } \\
\text { Working Group Coordinator \& } \\
\text { Specifications Developer }\end{array}$ \\
\hline
\end{tabular}





\section{FOREWORD}

This report contains the prismatic Phase II benchmark specification for the uncertainty analysis in high-temperature gas-cooled reactor modeling. The specification includes the prismatic high-temperature reactor design core model description, neutronics and thermal fluid exercise definitions, supporting data, and reporting templates for Phase II. 


\section{CONTENTS}

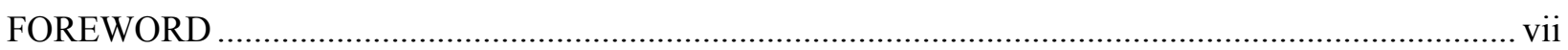

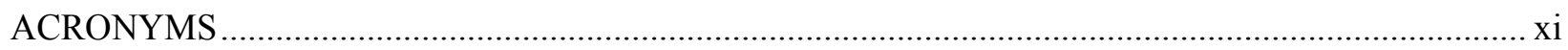

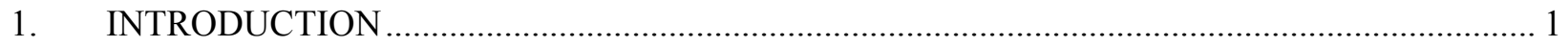

1.1 Phase I: Local (Lattice) Neutronics and Thermal Fluid Calculations .................................... 1

1.2 Phase II: Global (Core) Stand-alone Calculations ............................................................... 2

1.3 Phase III: Coupled Steady-State ............................................................................... 2

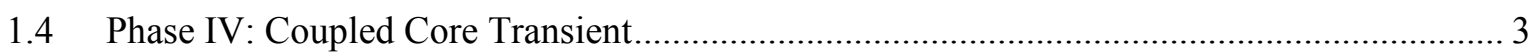

2. EXERCISES II-1a/b: BLOCK AND CORE DEPLETION STAND-ALONE

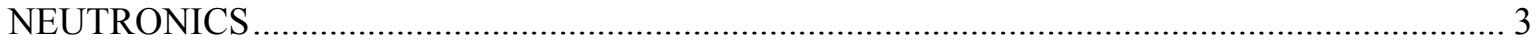

3. EXERCISE II-2: STAND-ALONE NEUTRONICS .............................................................. 7

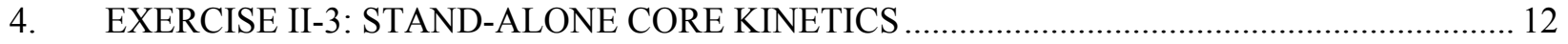

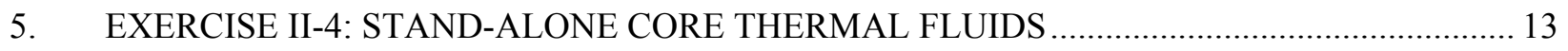

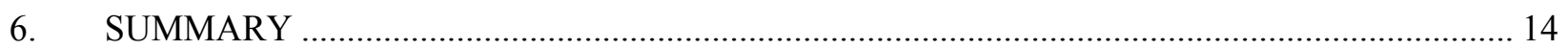

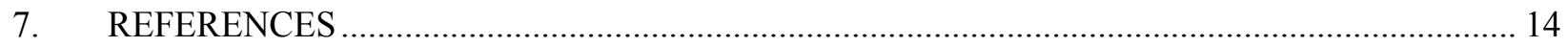

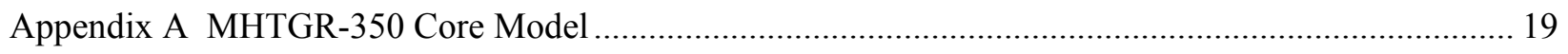

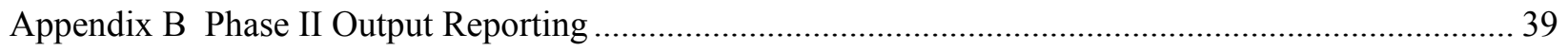

Appendix C Fuel and Graphite Thermo-Physical Properties............................................................... 45

Appendix D Manufacturer and Material Uncertainty Data for Phase II ............................................... 55

\section{FIGURES}

Figure 1. MHTGR-350 single block configuration........................................................................ 3

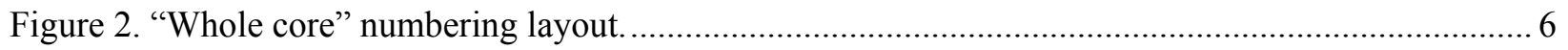

Figure 3. MHTGR-350 super cell around Block 26....................................................................... 7

Figure 4. Simplified (rotated) representation of the Exercise I-2c super cell. The "burned" region consists of a homogenous mixture of two depleted blocks and one fresh fuel block.................. 8

Figure 5. Representation of fuel super cells $k, l, m$ and $i$, as well as reflector super cell $r$........................ 9

Figure 6. Mixed core loading pattern: fresh (A) and depleted (B) fuel. ............................................... 10

Figure 7. $\mathrm{UC}_{0.5} \mathrm{O}_{1.5}$ fuel kernel nuclide densities for the depleted fuel block (Exercise I-2b). .................. 11

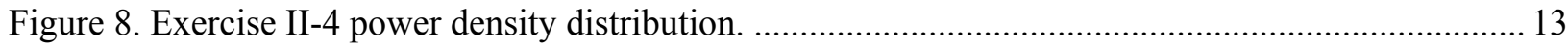

Figure A-1. MHTGR unit layout—axial (best available drawing). ........................................................ 20

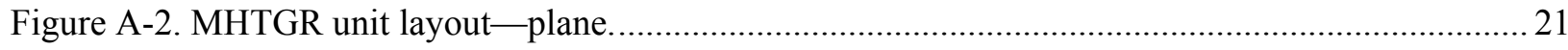

Figure A-3. Standard fuel element (units in inches) (best available drawing).......................................23 
Figure A-4. RSC fuel element (units in inches) (best available drawing).

Figure A-5. Hexagonal reflector element with control rod hole (units in inches) (best available

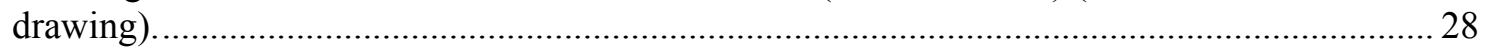

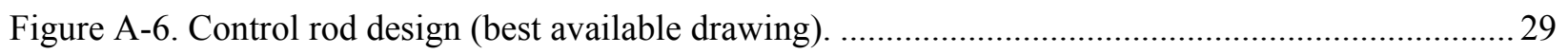

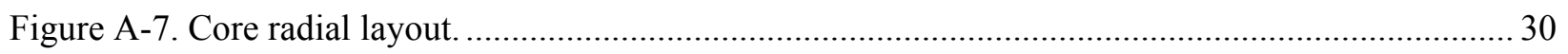

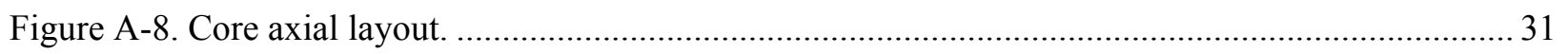

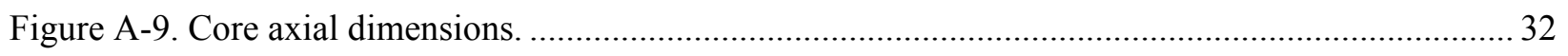

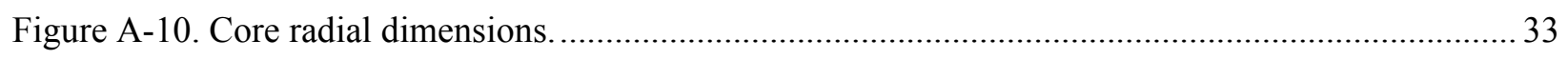

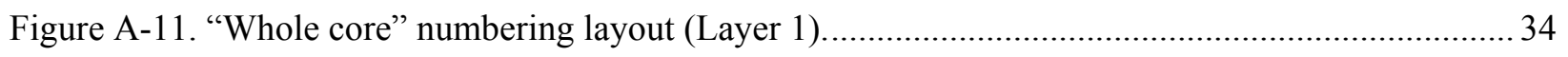

Figure A-12. Mixed core loading pattern: fresh (A) and depleted (B) fuel. ........................................... 34

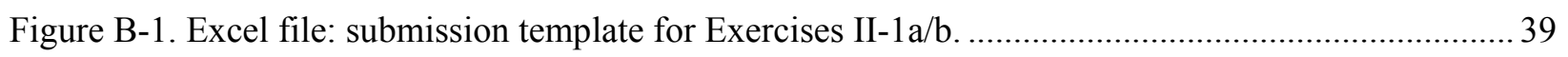

Figure C-1. Thermal conductivity of Grade H-451 graphite. ............................................................... 46

Figure C-2. Corrected matrix for the AMEC compact model. .............................................................50

\section{TABLES}

Table 1. TRISO and block dimensions for Exercise I-2 .................................................................. 4

Table 2. Number densities for the fresh fuel block (Exercise I-2a) ..................................................... 5

Table 3. Number densities for the depleted fuel block (Exercise I-2b) . .................................................... 11

Table 4. Exercise II-3 — reactivity insertion/removal transient .............................................................. 12

Table 5. Bypass flow distribution (nominal and uncertainty values)...................................................... 13

Table A-1. Major design and operating characteristics of the MHTGR-350......................................... 19

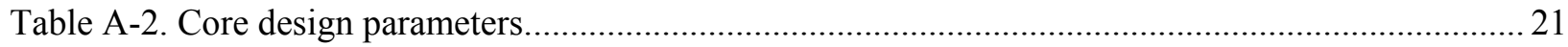

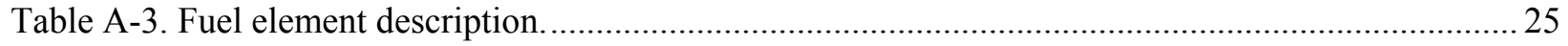

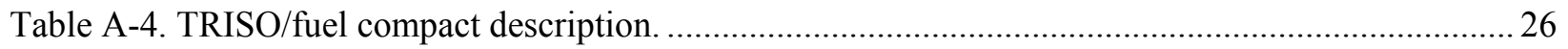

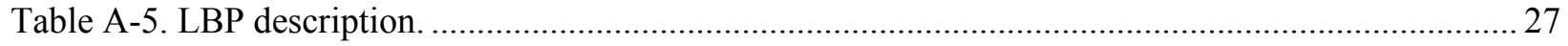

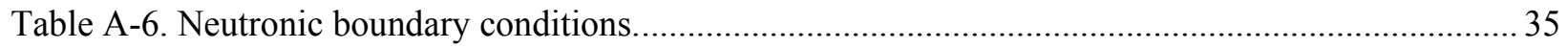

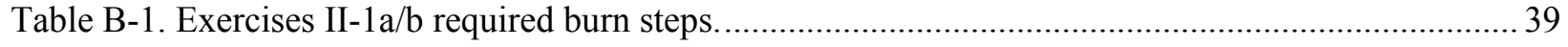

Table C-1. Thermo-physical properties of Grade H-451 graphite........................................................ 45

Table C-2. Pyrolitic and porous carbon thermo-physical properties. .................................................... 46

Table C-3. Compact matrix graphite thermo-physical properties.............................................................. 47

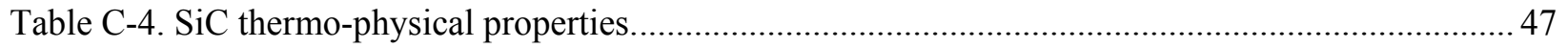

Table D-1. Number densities for Exercises II-1, II-2 and II-4-nominal and $1 \sigma$ uncertainties

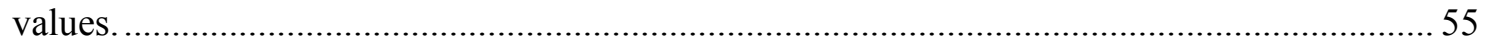

Table D-2. Exercises II-4input parameters - nominal and $1 \sigma$ uncertainties values..................................56 


\section{ACRONYMS}

AGR Advanced Gas Reactor

B.C. Boundary Condition

BP burnable poison

CRP Coordinated Research Project

DNE DIDO Nickle Equivalent

FBP lumped burnable poison

HFP hot full power

HTGR high-temperature gas-cooled reactor

IAEA International Atomic Energy Agency

IPyC inner pyrolitic carbon

LBP lumped burnable poison

MG multi-group

MHTGR modular high-temperature gas-cooled reactor

NEA Nuclear Energy Agency

OECD Organisation for Economic Cooperation and Development

OPyC outer pyrolitic carbon

PyC pyrolitic carbon

RCM Research Coordination Meeting

RPV reactor pressure vessel

RSC reserve shutdown control

RSS reserve shutdown material

$\mathrm{SiC} \quad$ silicon carbide

TRISO tristructural isotropic

UAM uncertainty analysis in modeling 


\title{
IAEA Coordinated Research Project on HTGR Physics, Thermal-Hydraulics, and Depletion Uncertainty Analysis
}

\author{
Prismatic HTGR Benchmark Specification: Phase II
}

\section{INTRODUCTION}

In February 2009, the Technical Working Group on Gas-Cooled Reactors of the International Atomic Energy Agency (IAEA) recommended that the proposed Coordinated Research Project (CRP) on the High-Temperature Gas-Cooled Reactor (HTGR) Uncertainty Analysis in Modeling (UAM) be implemented. This CRP is a continuation of the previous IAEA and Organisation for Economic Cooperation and Development (OECD)/Nuclear Energy Agency (NEA) international activities on verification and validation of available analytical capabilities for HTGR simulation for design and safety evaluations $[1,2,3]$. Within the framework of these activities different numerical and experimental benchmark problems were performed, and insight was gained about specific physics phenomena and the adequacy of analysis methods.

Because the prismatic design specification included in this report is based directly on the OECD/NEA Modular HTGR (MHTGR)-350 MW benchmark [4], participants in both activities can leverage their core models developed for the OECD/NEA benchmark for this CRP benchmark with only minor changes. The CRP on the HTGR UAM Phase II specifications is also directly linked to the Phase I specification document [5], since the core models required for Phase II exercises are constructed using the lattice models and cross-section libraries developed for Phase 1.

It was decided at the Third Research Coordination Meeting (RCM) in May 2017 that the initial scope of CRP activities will be reduced to match the formally approved remaining contract period (June 2019), as well as limited funding and resource availability. A summary of the revised Phases I-IV exercise definitions is provided here.

\subsection{Phase I: Local (Lattice) Neutronics and Thermal Fluid Calculations}

Exercises I-1 and I-2 are focused on the derivation of the multi-group (MG) and few-group microscopic cross-section libraries. The objective is to address the uncertainties due to the basic nuclear data, as well as the impact of processing the nuclear and covariance data, selection of MG structure, and double heterogeneity or self-shielding treatment. The intention is to propagate the uncertainties in evaluated nuclear data libraries (i.e., microscopic point-wise cross sections) into MG microscopic cross sections and to propagate the uncertainties from the MG microscopic cross sections into the few-group cross sections for use in Phase II.

Exercise I-1a consists of a homogeneous fuel region of homogenized tristructural isotropic (TRISO) fuel particles and matrix graphite, whereas Exercise I-1b requires the explicit modeling of the TRISO fuel particles to investigate their self-shielding effect on the MG microscopic cross sections.

Exercise I-2a requires a lattice calculation to be performed on a single fuel block at hot full power (HFP) conditions, while Exercise I-2b specifies the same problem at $100 \mathrm{MWd} / \mathrm{kg}-\mathrm{U}$ burnup. Exercise I-2c adds the spectral effects of the neighboring domain by performing a lattice calculation on a super cell, which consists of a fresh fuel block surrounded by a mixture of depleted and fresh fuel on one side and graphite reflector blocks on the other side. This calculation is also performed at HFP conditions. 
Exercises I-3 and I-4 are focused on the localized stand-alone fuel thermal response. The aim of the stand-alone thermal unit cell calculations is to isolate the effects of material and boundary input uncertainties on very simplified problems before the same input variations are applied to complex core problems (e.g., Phases II and III). Exercise I-3 requires a steady-state solution for a single fuel compact and coolant channel unit cell with a fixed bulk coolant temperature. Two sub-cases similar to Exercise I-1 are again defined here, taking into account the explicit modeling of heat transfer from the TRISO fuel particles to the matrix graphite. Exercise I-4 uses the same unit cell definition as described for Exercise I-3, but a time-dependent power excursion is prescribed, as opposed to constant steady-state power.

\subsection{Phase II: Global (Core) Stand-alone Calculations}

The global (or core) exercises defined for Phase II use the cross-section libraries and in some cases, the output uncertainties generated in Phase I, as part of the propagated input data. All Phase II calculations must be performed at HFP $(1,200 \mathrm{~K})$ conditions. Phase II exercises are as follows:

- Exercise II-1: Neutronics-block and core depletion. As the first variant of the depletion cases, the single block defined in Exercise I-2a is depleted up to $80 \mathrm{GWd} / \mathrm{MTU}$ as Exercise II-1a. For Exercise II-1b, a full-core depletion to the same burnup is requested. The Exercise II-1 depletion specifications were developed by Idaho National Laboratory and reported with nominal and uncertainty results in July 2017 [6]. The summarized exercise definitions will be included in this report for completeness.

- Exercise II-2: Neutronics—stand-alone core steady-state. Two full-core steady-state neutronics calculations at HFP conditions are to be performed using the given fresh (Exercise II-2a) and mixed (Exercise II-2b) core number densities, respectively. The fresh core model is identical to the starting point for Exercise II-1b, if participants elected to perform the depletion cases. The cross-section libraries developed in Exercise I-2 (e.g., fresh and depleted single blocks, and any super cells of the participants' choice) should be utilized for this core calculation.

- Exercise II-3: Neutronics - stand-alone core kinetics without feedback. This exercise involves a full-core calculation with reactivity being added and then returned to normal at hot full power conditions, but without any temperature feedback. The reactivity-induced transient is defined as control rod movement at normal speed to ensure that the delayed neutrons play a role (i.e., no prompt critical effects). The uncertainties in the kinetic parameters are added in this case, and only the mixed (fresh and depleted) core loading is considered.

- Exercise II-4: Thermal fluids-stand-alone core steady-state. The conditions at normal HFP operation are considered with the reactor core power distribution specified. No neutronics feedback exists. Variation in bypass flows and pebble packing fractions are some of the additional uncertainties to be taken into account, together with the material property uncertainties specified for Exercise I-3.

\subsection{Phase III: Coupled Steady-State}

Exercise III-1 requires a coupled calculation focused on the steady-state HFP neutronics/thermal-hydraulics core performance. Many of the uncertainties determined in the previous stand-alone cases (Exercises II-2 and II-4) will be propagated to this model. Only the mixed core loading is considered. 


\subsection{Phase IV: Coupled Core Transient}

Exercise IV-1 is a coupled mixed core transient at HFP conditions with full thermal (Exercise III-1) and kinetics feedback (Exercise II-3). It will be defined as a reactivity-induced power excursion due to a control rod withdrawal. The feedback effect from the rest of the power conversion unit is to be kept constant, (i.e., the focus is on the core response only). A mixed core consisting of fresh and depleted fuel will be investigated.

The first two CRP on the HTGR UAM documents released for the prismatic reactor design contains the specification for the Phase I exercises [5] and Exercise II-1 [6], respectively. The critical model information will be repeated here as well to allow independence of the two specification documents (see Appendix A for MHTGR-350 design detail). The specifications for Phases III and IV will be released in 2019 after scoping calculations have been completed at Idaho National Laboratory.

\section{EXERCISES II-1a/b: BLOCK AND CORE DEPLETION STAND-ALONE NEUTRONICS}

The specifications for the Phase II depletion exercise were developed in 2017 [6] and are summarized here for completeness. Participants can choose to submit results based on the single block (Exercise II-1a) and/or a full-core model (Exercise II-1b). Only HFP conditions (1,200 K) are considered for all Phase II exercises. The geometry for the simplified single MHTGR-350 hexagonal fuel blocks is shown in Figure 1 and Table 1. The fresh fuel block defined for Exercise I-2a includes six lumped burnable poison (LBP) compacts in the six corners of the block. The isotopic data (number densities) for this fuel block is listed in Table 2. For the depleted fuel block defined for Exercise I-2b (Figure 1 without the six green corner burnable poison [BP] compacts), it is assumed that all LBPs have been fully depleted and are replaced by H-451 block graphite. The fresh and depleted fuel blocks will be used in constructing the mixed core model defined for Exercise II- $2 b$.

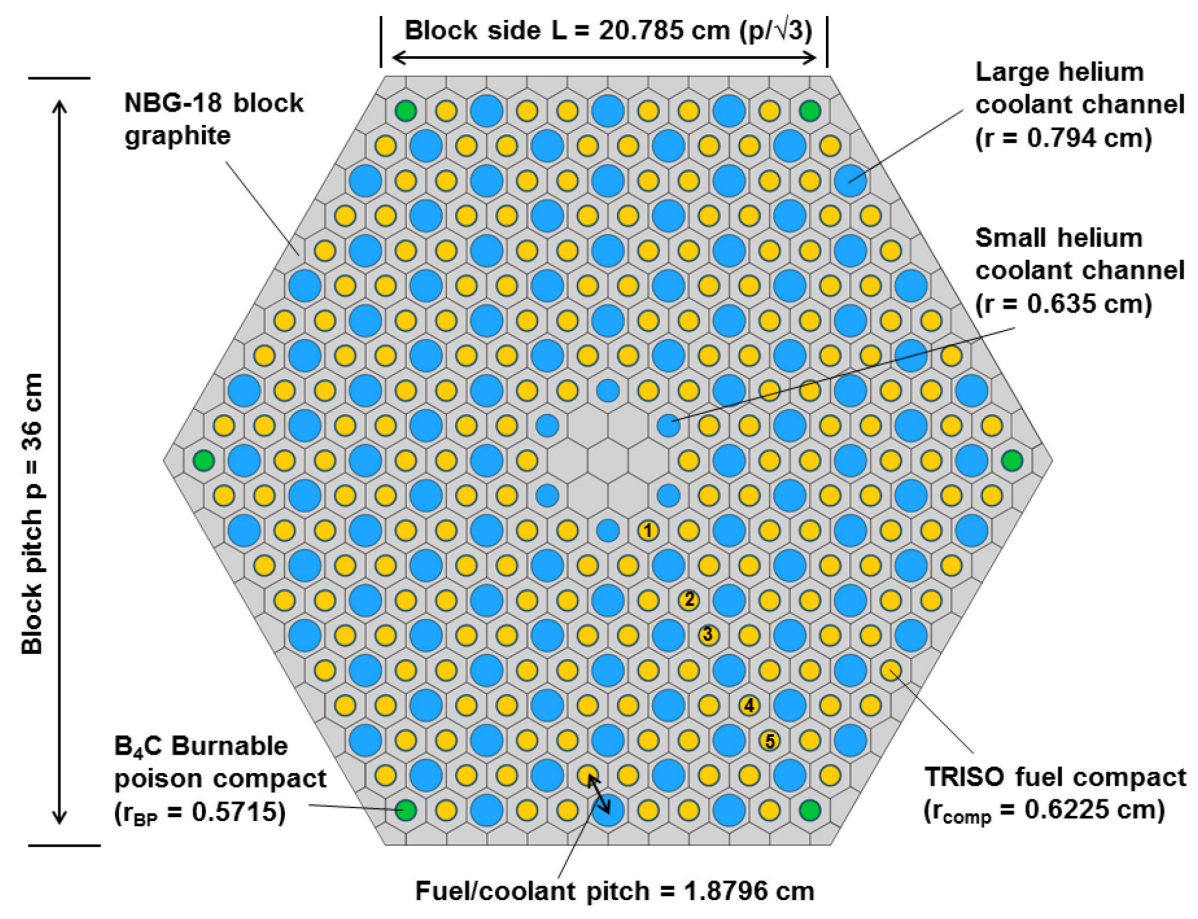

Figure 1. MHTGR-350 single block configuration. 
Table 1. TRISO and block dimensions for Exercise I-2.

\begin{tabular}{|c|c|c|c|}
\hline \multicolumn{2}{|c|}{ Parameter } & \multirow{2}{*}{$\begin{array}{l}\text { Dimension } \\
2.125 \mathrm{E}-02 \\
\end{array}$} & \multirow{2}{*}{$\begin{array}{c}\text { Unit } \\
\mathrm{cm}\end{array}$} \\
\hline TRISO fuel particle & $\mathrm{UC}_{0.5} \mathrm{O}_{1.5}$ kernel radius & & \\
\hline & Porous carbon buffer outer radius & $3.125 \mathrm{E}-02$ & $\mathrm{~cm}$ \\
\hline & $\begin{array}{l}\text { Inner pyrolitic carbon (IPyC) Outer } \\
\text { Reflector (OR) }\end{array}$ & $3.525 \mathrm{E}-02$ & $\mathrm{~cm}$ \\
\hline & Silicon carbide (SiC) OR & $3.875 \mathrm{E}-02$ & $\mathrm{~cm}$ \\
\hline & Outer pyrolitic carbon (OPyC) OR & $4.275 \mathrm{E}-02$ & $\mathrm{~cm}$ \\
\hline \multicolumn{2}{|c|}{ TRISO packing fraction } & 0.35 & - \\
\hline \multicolumn{2}{|l|}{ Fuel compact radius } & 0.6225 & $\mathrm{~cm}$ \\
\hline \multicolumn{2}{|l|}{ Gap radius } & 0.6350 & $\mathrm{~cm}$ \\
\hline \multicolumn{2}{|c|}{ Number of fuel compacts per block } & 210 & - \\
\hline \multirow[t]{3}{*}{ LBP particle } & Kernel radius & 0.0100 & $\mathrm{~cm}$ \\
\hline & Porous carbon buffer outer radius & 0.0118 & $\mathrm{~cm}$ \\
\hline & Pyrolitic carbon (PyC) outer radius & 0.0141 & $\mathrm{~cm}$ \\
\hline \multicolumn{2}{|c|}{ BP particle packing fraction } & 0.1090 & - \\
\hline \multicolumn{2}{|l|}{ BP compact radius } & 0.5715 & $\mathrm{~cm}$ \\
\hline \multicolumn{2}{|c|}{ Large coolant channel radius } & 0.7940 & $\mathrm{~cm}$ \\
\hline \multicolumn{2}{|c|}{ Number of large coolant holes } & 102 & - \\
\hline \multicolumn{2}{|c|}{ Small coolant channel radius } & 0.6350 & $\mathrm{~cm}$ \\
\hline \multicolumn{2}{|c|}{ Number of small coolant holes } & 6 & - \\
\hline \multicolumn{2}{|l|}{ Pin pitch } & 1.8796 & $\mathrm{~cm}$ \\
\hline \multicolumn{2}{|c|}{ Block flat-to-flat width } & 36.0 & $\mathrm{~cm}$ \\
\hline \multicolumn{2}{|c|}{ Block (compact) height } & 4.9280 & $\mathrm{~cm}$ \\
\hline
\end{tabular}


Table 2. Number densities for the fresh fuel block (Exercise I-2a).

\begin{tabular}{|c|c|c|c|}
\hline \multicolumn{2}{|c|}{ Number Densities } & Nuclide & $\mathrm{N}(\mathrm{at} / \mathrm{b}-\mathrm{cm})$ \\
\hline \multirow[t]{11}{*}{ TRISO fuel particle } & \multirow{4}{*}{$\mathrm{UC}_{0.5} \mathrm{O}_{1.5}$ kernel } & ${ }^{235} \mathrm{U}$ & $3.6676 \mathrm{E}-03$ \\
\hline & & ${ }^{238} \mathrm{U}$ & $1.9742 \mathrm{E}-02$ \\
\hline & & ${ }^{16} \mathrm{O}$ & $3.5114 \mathrm{E}-02$ \\
\hline & & Graphite & $1.1705 \mathrm{E}-02$ \\
\hline & Porous carbon & Graphite & $5.2646 \mathrm{E}-02$ \\
\hline & IPyC & Graphite & $9.5263 \mathrm{E}-02$ \\
\hline & \multirow[t]{4}{*}{$\mathrm{SiC}$} & ${ }^{28} \mathrm{Si}$ & $4.4159 \mathrm{E}-02$ \\
\hline & & ${ }^{29} \mathrm{Si}$ & $2.2433 \mathrm{E}-03$ \\
\hline & & ${ }^{30} \mathrm{Si}$ & $1.4805 \mathrm{E}-03$ \\
\hline & & Graphite & $4.7883 \mathrm{E}-02$ \\
\hline & OPyC & Graphite & $9.5263 \mathrm{E}-02$ \\
\hline \multirow[t]{5}{*}{ BP particle } & \multirow[t]{3}{*}{ Kernel } & ${ }^{10} \mathrm{~B}$ & $2.1400 \mathrm{E}-02$ \\
\hline & & ${ }^{11} \mathrm{~B}$ & $8.6300 \mathrm{E}-02$ \\
\hline & & Graphite & $2.6900 \mathrm{E}-02$ \\
\hline & Buffer & Graphite & $5.0200 \mathrm{E}-02$ \\
\hline & $\mathrm{PyC}$ & Graphite & $9.3800 \mathrm{E}-02$ \\
\hline \multicolumn{2}{|l|}{ Fuel compact matrix } & Graphite & $7.2701 \mathrm{E}-02$ \\
\hline \multicolumn{2}{|l|}{ BP compact matrix } & Graphite & $7.2701 \mathrm{E}-02$ \\
\hline \multicolumn{2}{|l|}{ Coolant channels } & ${ }^{4} \mathrm{He}$ & $2.4600 \mathrm{E}-05$ \\
\hline \multicolumn{2}{|l|}{ H-451 block graphite } & Graphite & $9.2756 \mathrm{E}-02$ \\
\hline
\end{tabular}


For Exercise II-1b, a core model consisting of fresh fuel must be constructed, using the few-group cross-section library created in Exercise I-2a. The fresh core model should use the same fresh fuel block cross-section library and isotopics in all 22 fuel locations and 10 axial layers (220 in total). The fuel blocks are identified in Figure 2 as the region between the blue and red lines (i.e., Blocks 8-21, 23-26, and 28-31. There are no radial or axial variations in the composition or cross-section representation of the fuel and reflector blocks, and the control rods are fully withdrawn from the core.

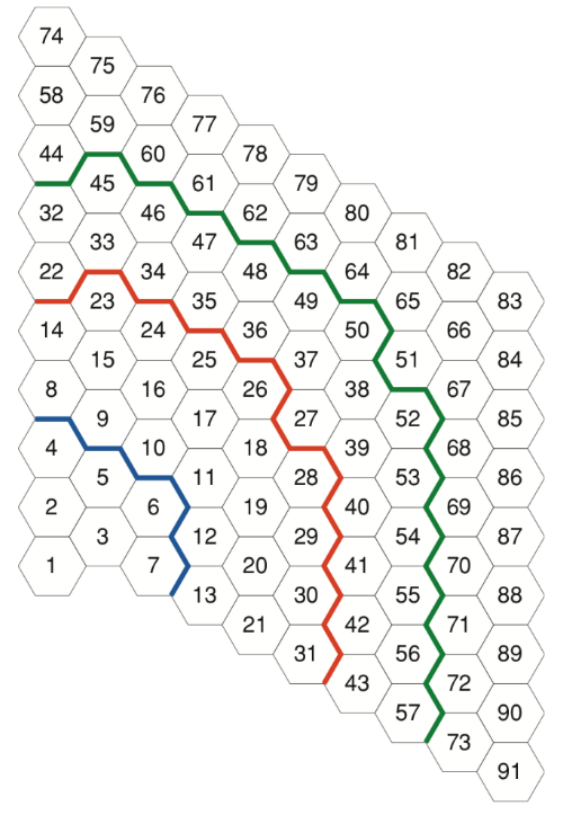

Figure 2. "Whole core" numbering layout.

The choice of reflector region representation is left to the participants - a single reflector isotopics and cross-section set can be used everywhere, and/or additional cross-section libraries can be created accounting for spectral effects near the core, for example. The reserve shutdown and control rod blocks (see Appendix A for more detail on the MHTGR-350 core design) are not treated separately, and both are assumed to be identical to the solid reflector blocks. The data required to construct the core model (e.g., fuel and reflector block dimensions and isotopics) is listed in Appendix A, Table A-3 and Table A-4.

As a minimum requirement, the results of the single block model is requested to allow data comparisons. The output data requested from the participants for comparison of Exercises II- $1 \mathrm{a} / \mathrm{b}$ data is specified in Appendix B.

Input uncertainties can arise from:

- $\quad \mathrm{MG}$ cross-section uncertainties (MG cross-section covariance matrix)

- Uncertainties associated with methods and modeling approximations utilized in lattice physics codes

- Fuel/assembly manufacturing uncertainties.

Propagation of cross-section uncertainties from the lattice models (Exercises I-2a/b/c) to the core models (Phase II) is achieved by using the libraries generated in Phase I in the Phase II core models. Methodological uncertainties, which are associated with methods and modeling approximations utilized in lattice physics codes, should be assessed by participants as a separate effort, but a comparison of this class of uncertainties is beyond the scope of the benchmark. Participants should also perform spatial and angular discretization convergence studies with their lattice physics codes to remove the uncertainties associated with numerical approximations (numerical method uncertainties). 
The third source of input uncertainties is fuel/assembly manufacturing uncertainties such as enrichment, pellet density, cladding dimensions, BP concentration, and assembly geometry. Assignment of uncertainty measures in the form of probability distribution functions are provided in Appendix D. The same input uncertainties as defined for Exercise I-2 should be applied to Exercise II-1. This information is of secondary importance (the main focus is on cross-section uncertainties), but participants are encouraged to submit an assessment of these uncertainties, either in combination with the cross-section data uncertainties or as a stand-alone uncertainty quantification.

\section{EXERCISE II-2: STAND-ALONE NEUTRONICS}

The Phase II core models require cross-section and isotopic data to be assigned to the various fuel and reflector blocks, as described in Section 2 and Appendix A. The use of reflective boundary conditions for fuel blocks next to the inner or outer reflectors leads to significant spectral variances, because these blocks are not surrounded by an infinite lattice of fuel blocks. An example of a super cell or mini-core located around a core periphery fuel block was defined as Exercise I-2c (Figure 3). In this example, Block 26 is surrounded by reflector blocks on the right and top boundaries, and by one fresh (Block 17) and two depleted fuel blocks (Blocks 18 and 25). The blocks containing fuel are homogenized using the relative contributions of two depleted fuel blocks and one fresh fuel block, as shown in Figure 4. The central fresh fuel block is modeled in its heterogeneous detail (LBP and TRISO compacts) to create the cross-section library for use in Phase II core models.

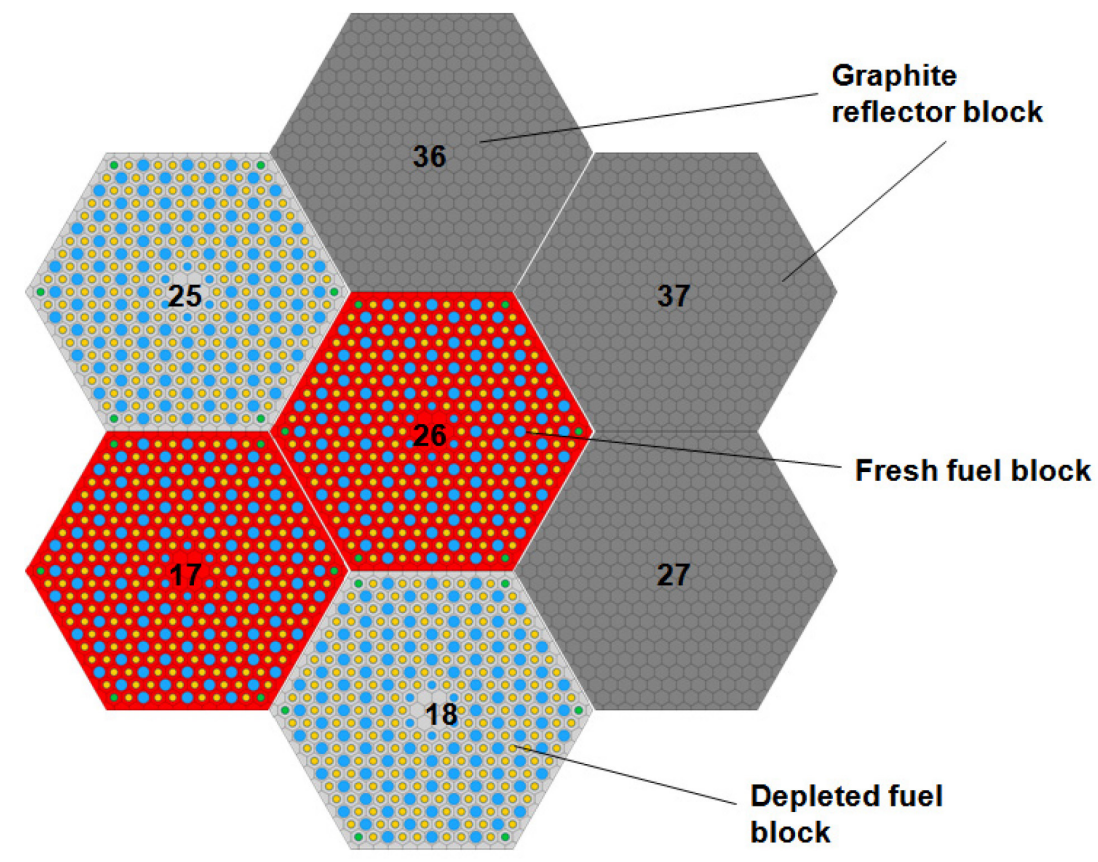

Figure 3. MHTGR-350 super cell around Block 26. 


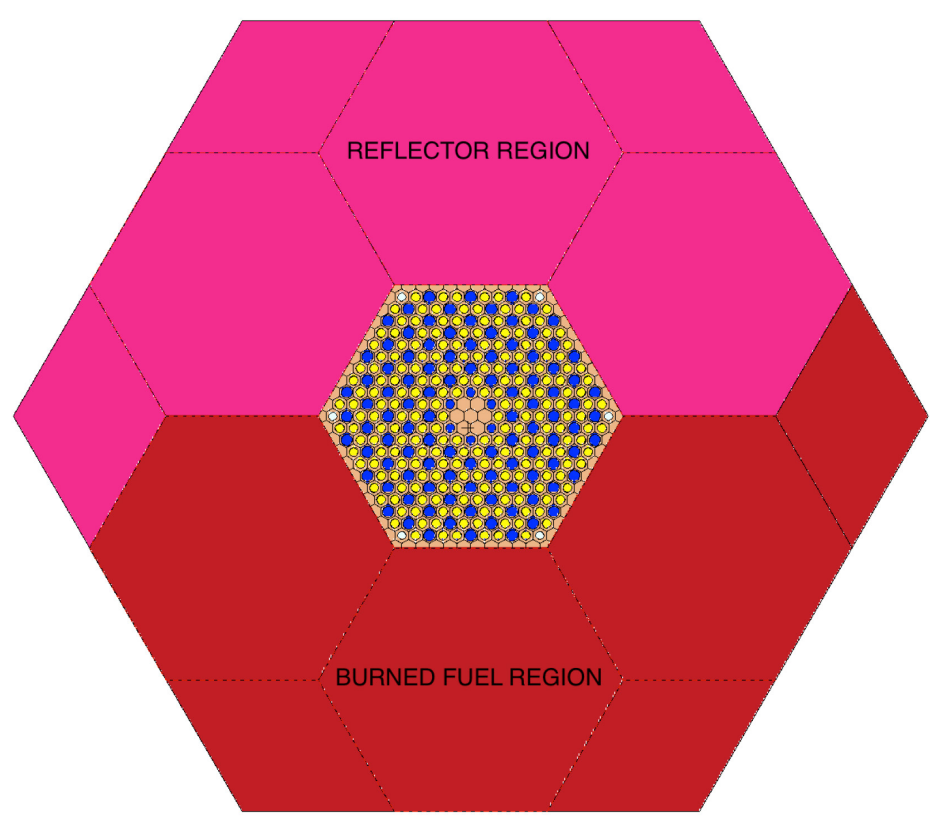

Figure 4. Simplified (rotated) representation of the Exercise I-2c super cell. The "burned" region consists of a homogenous mixture of two depleted blocks and one fresh fuel block.

Several super cells can be constructed from the MHTGR-350 core loading, as shown in Figure 5. Super cells $k, l$, and $m$ represent fuel blocks (F) located in the outer fuel ring next to the outer reflector with a varying number of graphite reflector blocks (R), while cell $i$ is surrounded by fuel elements only. Cell $i$ is representative of the spectral environment for Block 17 in Figure 3, for example. Participants are free to choose the representation of spectral effects in their core models, ranging from a single block everywhere to cross sections produced by several configurations of these super cells. A similar approach can be used for the reflector block cross sections, which can either be a single graphite block infinitely reflected, or a more complex super cell (e.g., cell $r$ in Figure 5). 

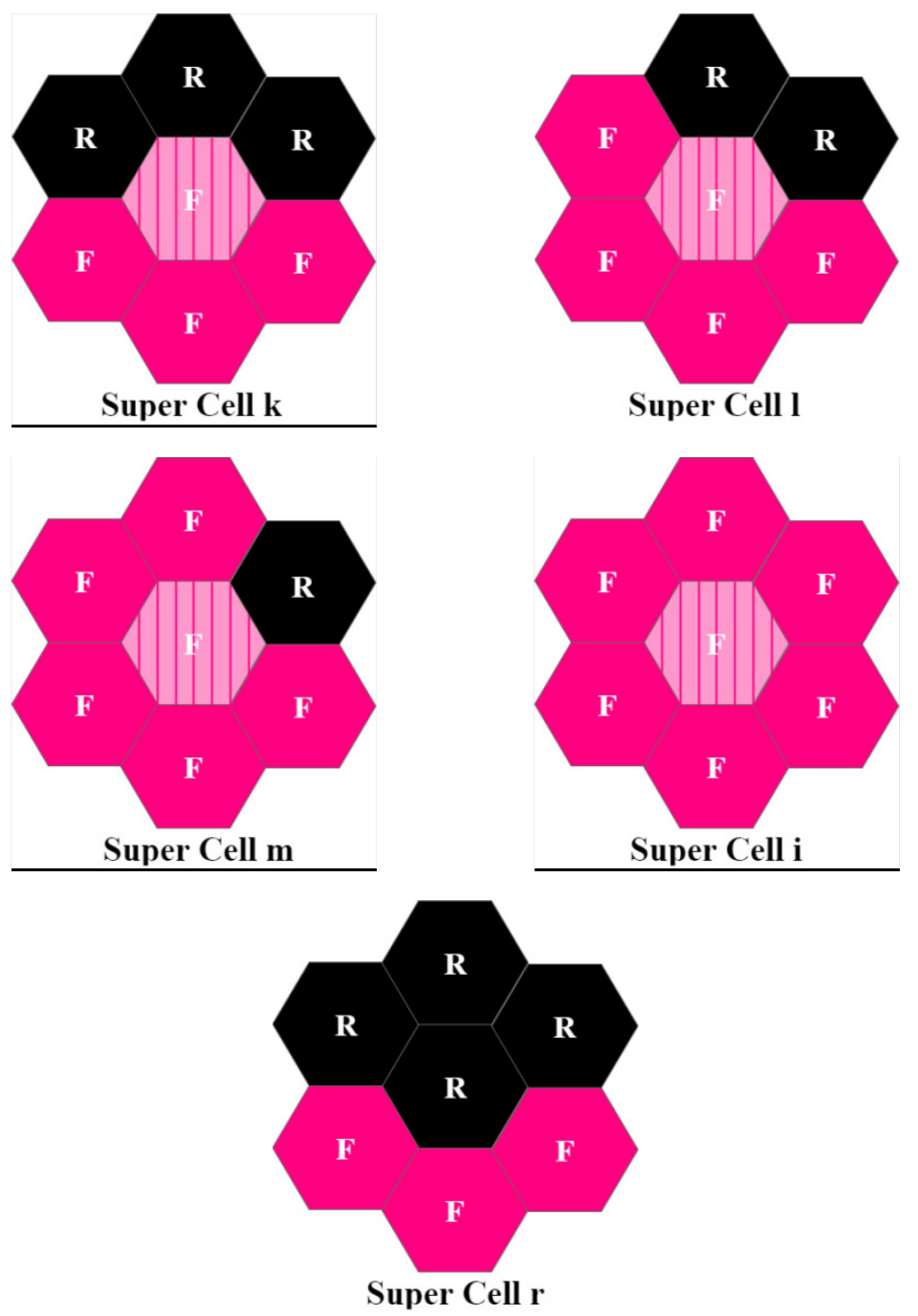

Figure 5. Representation of fuel super cells $k, l, m$ and $i$, as well as reflector super cell $r$. 
Two core loading patterns will be analysed for Phase II of the CRP:

- Exercise II-2a: The first core is a fresh core at HFP conditions and with no control rods inserted. This core is identical to the starting point of Exercise II-1b. The cross-section libraries assigned to the fresh fuel blocks should be generated using the Exercise I-2a fresh fuel block lattice model to propagate the cross-section co-variance data from Phase I to Phase II. The use of a periphery super cell for the fresh core is left to the participants' discretion. The most basic configuration (i.e., a single fresh cross-section library assigned to all 220 fresh fuel blocks) is requested as the minimum set for comparison. This fresh core model will not be used in subsequent phases.

- Exercise II-2b: The second core will be used for the transient defined in Phase IV. A mixed core at HFP conditions is constructed using alternating fresh and depleted fuel blocks in the pattern shown in Figure 6. The control rods described in Appendix A, Figure A-6, are also added to Block 33 in Figure 2. The isotopics for the homogenized Block 33 will be provided for participants to develop a "rodded" cross-section data set that will be used to determine control rod worth and provide the reactivity insertion in Phase IV. Since the spectral effects of the plutonium isotopes in the depleted fuel is different from the fresh fuel isotopes, more super cells accounting for both fresh and depleted central blocks could possibly be required. The most basic version of this exercise will use the fresh and depleted single block isotopic composition definitions and cross-section libraries, and no super cells at the core periphery.

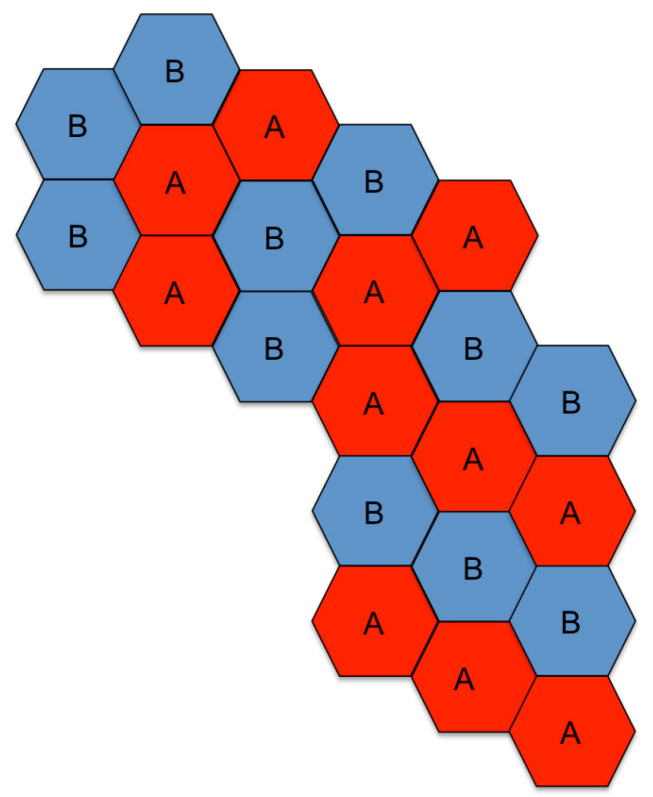

Figure 6. Mixed core loading pattern: fresh (A) and depleted (B) fuel.

It is important to note that although the same reactor design information is used for both the OECD/NEA and IAEA CRP benchmarks, the definition of the core states differs significantly. For the OECD/NEA MHTGR-350 benchmark, the end of equilibrium cycle nuclide data was obtained from General Atomics. No fresh core case was defined, and the mixed core consisted of 220 fuel blocks that had been shuffled and reloaded after one and two burn cycles, respectively. Each of the 220 fuel blocks (22 fuel blocks in 10 axial layers) had a unique nuclide composition, and therefore cross-section libraries, based on their specific exposure histories. 
In contrast to this, the IAEA CRP on the HTGR UAM simplified this approach by specifying a fresh core that consists of only fresh fuel everywhere for Exercise II-2a (i.e., a single cross-section and isotopic data set), as well as a mixed core that contains fresh and depleted fuel blocks (Exercise II-2b) in 10 identical axial core layers (Figure 6). Although the mixed core packing pattern is the same for both benchmarks, the depletion state of the burned blocks are not the same. Direct comparisons of eigenvalues, power densities, and temperatures between the two benchmarks are therefore not possible. This is judged to be acceptable since the primary purpose of the IAEA CRP on the HTGR UAM is the comparison of uncertainty and sensitivity parameters, not best-estimate/nominal values.

In order to reduce the amount of required calculation memory, it was accepted at the second RCM in 2015 that the full Serpent nuclide list obtained in Exercise I-2b be reduced to a smaller number of important nuclides. For the Phase II specifications, it is recommend that SCALE users utilize the standard 94 nuclides included in the SCALE/TRITON sequence as option "addnux=2". (For more detail, see the SCALE 6.1 User Manual7, Table T1.3.4.), but more or less isotopes can be included based on participants' code capabilities and judgement. The isotopic composition of the depleted fuel blocks is included in Table 3, but since the data set for the fuel kernels is too large to display in the table, it is embedded in an Excel file object (Figure 7).

Table 3. Number densities for the depleted fuel block (Exercise I-2b).

\begin{tabular}{|l|l|c|c|}
\hline \multicolumn{2}{|c|}{ Number Densities } & Nuclide & N (at/b-cm) \\
\hline \multirow{5}{*}{ TRISO fuel particle } & $\mathrm{UC}_{0.5} \mathrm{O}_{1.5}$ kernel & See data file (Figure 7) & See data file (Figure 7) \\
\cline { 2 - 4 } & Porous carbon & Graphite & $5.2646 \mathrm{E}-02$ \\
\cline { 2 - 4 } & $\mathrm{IPyC}$ & Graphite & $9.5263 \mathrm{E}-02$ \\
\cline { 2 - 4 } & \multirow{3}{*}{$\mathrm{SiC}$} & ${ }^{28} \mathrm{Si}$ & $4.4159 \mathrm{E}-02$ \\
\cline { 3 - 4 } & & ${ }^{29} \mathrm{Si}$ & $2.2433 \mathrm{E}-03$ \\
\cline { 2 - 4 } & ${ }^{30} \mathrm{Si}$ & $1.4805 \mathrm{E}-03$ \\
\cline { 2 - 4 } & & Graphite & $4.7883 \mathrm{E}-02$ \\
\cline { 2 - 4 } & OPyC & Graphite & $9.5263 \mathrm{E}-02$ \\
\hline Fuel compact matrix & Graphite & $7.2701 \mathrm{E}-02$ \\
\hline BP compact matrix & Graphite & $7.2701 \mathrm{E}-02$ \\
\hline Coolant channels & ${ }^{4}$ He & $2.4600 \mathrm{E}-05$ \\
\hline H-451 block graphite & Graphite & $9.2756 \mathrm{E}-02$ \\
\hline
\end{tabular}

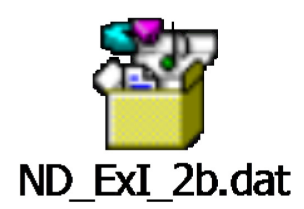

Figure 7. $\mathrm{UC}_{0.5} \mathrm{O}_{1.5}$ fuel kernel nuclide densities for the depleted fuel block (Exercise I-2b).

The output data requested from the participants for comparison of Exercises II- $2 \mathrm{a} / \mathrm{b}$ data is specified in Appendix B. The output data that will be compared include the nominal and uncertainty eigenvalues (and associated uncertainty), radial power density distributions on three axial core levels, and axial power offsets. The control rod worth uncertainties can also be assessed by using the provided homogenized control rod information for Block 33. The control rod worth is determined by withdrawing the Block 33 
control rods from their nominal location in the first two fuel blocks to the bottom of the first top reflector block (a distance of $158.6 \mathrm{~cm}$ ).

As indicated in Section 2, propagation of cross-section uncertainties from the lattice models (Exercises I-2a/b/c) to the core models (Phase II) is achieved by using the libraries generated in Phase I in the Phase II core models. The fuel/assembly manufacturing uncertainties listed in Appendix D can likewise be used to assess the combination of cross-section and manufacturing data uncertainties on the core models. The quantification of the latter uncertainties is an optional exercise.

\section{EXERCISE II-3: STAND-ALONE CORE KINETICS}

The stand-alone core kinetics exercise is designed to isolate the effect of uncertainties in the values of the delayed neutron parameters (yields and lifetimes), without the compensating effect of temperature (fuel, moderator, and reflector) feedbacks. It uses the mixed HFP core model created in Exercise II- $2 \mathrm{~b}$ as the starting point of a global reactivity insertion transient over a period of 320 seconds. The transient is representative of a full control rod withdrawal at $1 \mathrm{~cm} / \mathrm{s}$ from the nominal control rod insertion depth. The relatively slow control rod withdrawal speed was chosen to ensure that this event stays below the prompt-critical threshold. Since the rods are inserted in the upper two fuel blocks only, a full withdrawal from 158.6 to $0 \mathrm{~cm}$ will take 158.6 seconds.

It was shown in the OECD/NEA MHTGR-350 benchmark results obtained for Exercise 1 that the control rods are worth between 850 and $1,000 \mathrm{pcm}$ at $1,200 \mathrm{~K}(0.85-1.0 \%)^{8}$. To ensure that all participants insert the same amount of reactivity during this transient, an actual control rod withdrawal will not be required, since the rod worths between the various models will differ. A global reactivity insertion of $1 \%$ over 158.6 seconds is used as a test of the kinetic behaviour of the core, and specifically the role that delayed neutrons play in the evolution of the core power.

Since this exercise does not include temperature feedback (i.e., all temperatures remain constant at $1,200 \mathrm{~K})$, the total core power will keep increasing until the additional reactivity is removed again. Following the specification suggested for the lighter-water reactor UAM core kinetics case, a 1\% reactivity removal is started at 200 seconds to "return" the control rods to their nominal location at $158.6 \mathrm{~cm}$. The sequence of events is indicated as a function of time in Table 4 .

Table 4. Exercise II-3 - reactivity insertion/removal transient

\begin{tabular}{|c|l|}
\hline $\begin{array}{c}\text { Time } \\
(\mathrm{s})\end{array}$ & \multicolumn{1}{c|}{ Transient Description } \\
\hline $0-158.6$ & $\begin{array}{l}\text { Withdraw all control rods at } 1 \mathrm{~cm} / \mathrm{s} \text { from } 158.6 \mathrm{~cm} \text {. This is equivalent to a } 1 \% \text { reactivity } \\
\text { insertion over this period. }\end{array}$ \\
\hline $158.6-200.0$ & Track core power evolution. \\
\hline $200.0-358.6$ & $\begin{array}{l}\text { Insert all control rods at } 1 \mathrm{~cm} / \mathrm{s} \text { to } 158.6 \mathrm{~cm} . \text { This is equivalent to a } 1 \% \text { reactivity } \\
\text { removal over this period. }\end{array}$ \\
\hline $358.6-400.0$ & Track core power evolution. \\
\hline 400.0 & End of transient. \\
\hline
\end{tabular}

The output data requested from the participants for comparison of Exercise II-3 data is specified in Appendix B. The output data that will be compared include the nominal and associated uncertainty of the total core power, radial power density distributions on three axial core levels, and axial power offsets.

Since the same lattice libraries are used for the propagation of cross-section uncertainties, the time-dependent effect of cross-section co-variance uncertainties can also be assessed during this event (at 0 seconds, Exercises II- $2 \mathrm{~b}$ and II-3 are equivalent). The additional component required for this exercise is uncertainty information about the delayed neutron yields (production) and generation lifetimes (typically 
in six groups). This information is currently not fully available, but it is expected that the next release of the SCALE code, for example, will contain delayed neutron uncertainty data for the first time.

In addition to the kinetics and cross-section uncertainties, the fuel/assembly manufacturing uncertainties listed in Appendix D can also be added to this transient, either as a stand-alone contribution or as a combination of the three input data uncertainties. The quantification of the manufacturing uncertainties is an optional exercise.

The uncertainties assessed in Exercise II-3 will not be propagated to the final Exercise IV-1 control rod transient, since the two exercises are identical apart from the addition of temperature feedback effects.

\section{EXERCISE II-4: STAND-ALONE CORE THERMAL FLUIDS}

Exercise II-4 is defined as a HFP thermal fluid-only steady-state simulation (i.e., the power density distribution is fixed and there is no neutronics feedback). In the context of the CRP on the HTGR UAM, it does not make use of any propagated uncertainty information from Phase I, but the variances in the figures of merit defined for this stand-alone case (e.g., fuel temperatures and mass flow rates) will be compared with the coupled steady-state Exercise III-1 data. This case therefore allows quantification of the thermal fluid input uncertainties originating from material properties, boundary conditions, heat transfer correlations, etc.

The power density distribution in the fuel blocks is included here as an embedded Excel file object (Figure 8).

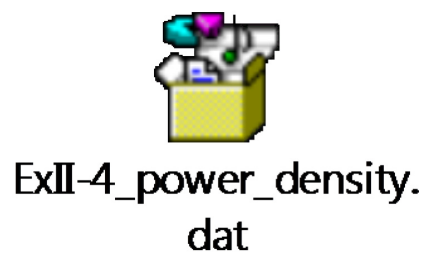

Figure 8. Exercise II-4 power density distribution.

A series of best-estimate cases were specified for the OECD/NEA MHTGR-350 benchmark, Phase I, as Exercises $2 \mathrm{a} / \mathrm{b} / \mathrm{c} / \mathrm{d}$ [4]. Two important aspects of thermal fluid simulation were varied:

- The material thermo-physical properties (e.g., conductivity, specific heat, and emissivity) were defined using either constant values (Exercises $2 \mathrm{a} / \mathrm{b}$ ) or as functions of temperature and fluence (Exercises 2c/d), as shown in Appendix C.

- The 2-5 mm gaps between the core and reflector blocks lead to a significant helium "leak" flow that bypasses the main engineered core coolant path through the fuel blocks. These bypass flows vary between 10 and $20 \%$ of the total flow, and result in lower graphite temperatures in the regions outside the core. The effect of bypass flows was assessed for the OECD benchmark in Exercises 2a/b, where the flows (in percent) for seven bypass flow channels were defined (as listed in Table 5). The standard deviation of these bypass flows are also included in Table 5. The changes in the bypass flows are driven by dimensional variations in the graphite block axial and radial geometry. Reactor-grade graphite typically shrinks during the first few years of exposure to high-energy neutrons, and reaches a turnaround point after about 4-6 years before it starts swelling. The variation listed in Table 5 is an attempt to assess the effect that these dimensional changes will have on the component temperatures.

Table 5. Bypass flow distribution (nominal and uncertainty values). 


\begin{tabular}{|l|c|c|}
\hline \multicolumn{1}{|c|}{ Component } & $\begin{array}{c}\text { Nominal Values } \\
(\% \text { of Total Flow) }\end{array}$ & $\begin{array}{c}\text { 1 } \sigma \text { Standard Deviation } \\
(\% \text { of Bypass Flow) }\end{array}$ \\
\hline In-core & 1.50 & 10.0 \\
\hline Inner reflector & 0.50 & 20.0 \\
\hline Inner control rod cooling & 1.20 & 20.0 \\
\hline Outer control rod cooling & 1.80 & 20.0 \\
\hline Outer reflector (first ring) & 1.38 & 20.0 \\
\hline Outer reflector (second ring) & 1.62 & 15.0 \\
\hline Permanent side reflector & 3.00 & 10.0 \\
\hline & 11.00 & - \\
\hline
\end{tabular}

For the CRP on the HTGR UAM, a fluence representative of the Advanced Gas Reactor (AGR)-1 irradiation history was selected as input for the graphite thermal conductivity correlations (see Appendix D, Table D-2, for more detail, where the nominal and uncertainty variations of the thermal fluids boundary conditions and the thermo-physical material properties are specified).

Exercise II-4 uses the temperature-dependent correlations and their uncertainties in Appendix D, Table D-2, as well as the bypass flows defined in Table 5 to determine the effect of these uncertainties on the fuel, moderator, and reflector temperatures. The output data requested from the participants for comparison of Exercise II-4 data is specified in Appendix B. The output data that will be compared include the nominal and associated uncertainty of the fuel, moderator and reflector temperatures, and bypass mass flow rate distribution.

\section{SUMMARY}

The specifications for all the prismatic high-temperature reactor exercises included in Phase II of the CRP on the HTGR UAM were presented. The information included exercise descriptions, neutronic and thermal-hydraulic data sets, support data, and required data sets for comparison. This report will be updated with participants' comments after the fifth RCM, planned for May 2018 in Vienna, if required.

\section{REFERENCES}

1. International Atomic Energy Agency, Evaluation of High Temperature Gas Cooled Reactor Performance: Benchmark Analysis Related to Initial Testing of the HTTR and HTR-10, IAEA-TECDOC-1382, November 2003, pp. 346.

2. Reitsma, F., et al., "The OECD/NEA/NSC PBMR400 MW Coupled Neutronics Thermal Hydraulics Transient Benchmark - Steady-State Results and Status," Proceedings of PHYSOR-2008 Conference, International Conference on the Physics of Reactors, "Nuclear Power: A Sustainable Resource," Casino-Kursaal Conference Center, Interlaken, Switzerland, September 14-19, 2008.

3. Strydom, G., et al., "The OECD/NEA/NSC PBMR 400 MW Coupled Neutronics Thermal Hydraulics Transient Benchmark: Transient Results," Proceedings of PHYSOR-2010 Conference, International Conference on the Physics of Reactors, Pittsburgh, PA, U.S.A., May 2010.

4. Ortensi, J., et al. "Benchmark of the Modular High-Temperature Gas-Cooled Reactor 350 MW Core Design.” Volumes I and II, NEA/NSC/R(2017)4, February 2018. 
5. Strydom, G. and F. Bostelmann, IAEA Coordinated Research Project on HTGR Physics, Thermal Hydraulics, and Depletion Uncertainty Analysis - Prismatic HTGR Benchmark Definition: Phase I, INL/EXT-15-34868, Idaho National Laboratory, Rev. 1, February 2017.

6. Rouxelin, P. and G. Strydom, IAEA CRP on HTGR UAM: Specifications for Phase II Exercise 1 (Depletion) and Nominal Results, INL/LTD-17-41017, Idaho National Laboratory, Rev. 0, July 2017.

7. B.T. Rearden, M.A. Jessee, "Scale Code System", ORNL/TM-2005/39, version 6.2 April 2016.

8. J. Ortensi, "OECD/NEA Coupled Neutronic/Thermal-Fluids Benchmark of the MHTGR-350 MW Core Design: Results for Phase-I Exercise 1”, OECD Draft version, December 2017. 
Appendix A

\section{MHTGR-350 Core Model}




\section{Appendix A}

\section{MHTGR-350 Core Model}

The design information required to develop the neutronics stand-alone full-core model of the modular high-temperature gas-cooled reactor (MHTGR)-350 design is described in this appendix. The data relevant to the neutronics Exercises II-1, II-2, and II-4 are listed first, followed by the thermal fluid information required for the simulation of Exercises II-3 and II-4. For the neutronics stand-alone exercises, a uniform isothermal temperature of $1,200 \mathrm{~K}$ is assumed for all structures, while a fixed power distribution is provided for the stand-alone thermal fluid Exercise II-3. The information provided is based on the official first release of the Organisation for Economic Cooperation and Development/Nuclear Energy Agency MHTGR-350 benchmark specification [1].

\section{MHTGR-350 Nuclear Power Plant}

The MHTGR-350 is a General Atomics design that was developed (but never built) in the 1980s. The main characteristics of the design are summarized in Table A-1. The reactor vessel contains the reactor core, reflectors, and associated neutron control systems; core support structures; shutdown cooling heat exchanger; and motor-driven circulator. The steam generator vessel houses a helically coiled steam generator bundle, as well as the motor-driven main circulator. The pressure-retaining components are constructed of steel and the restraining structures within the reactor vessel are a steel and graphite core support structure at the bottom and a metallic core barrel around the periphery of the side reflectors.

Table A-1. Major design and operating characteristics of the MHTGR-350.

\begin{tabular}{|l|c|}
\hline \multicolumn{1}{|c|}{ MHTGR Characteristic } & Value \\
\hline Installed thermal capacity & $350 \mathrm{MW}(\mathrm{t})$ \\
\hline Installed electric capacity & $165 \mathrm{MW}(\mathrm{e})$ \\
\hline Core configuration & Annular \\
\hline Fuel & $\begin{array}{c}\text { Prismatic hex-block fueled with uranium oxycarbide fuel } \\
\text { compact of } 15.5 \mathrm{wt} \% \text { enriched }{ }^{235} \mathrm{U} \text { (average) }\end{array}$ \\
\hline Primary coolant & Helium \\
\hline Primary coolant pressure & $6.39 \mathrm{MPa}$ \\
\hline Moderator & Graphite \\
\hline Core outlet temperature & $687^{\circ} \mathrm{C}$ \\
\hline Core inlet temperature & $259^{\circ} \mathrm{C}$ \\
\hline Mass flow rate & $157.1 \mathrm{~kg} / \mathrm{s}$ \\
\hline Reactor vessel height & $22 \mathrm{~m}$ \\
\hline Reactor vessel outside diameter & $6.8 \mathrm{~m}$ \\
\hline
\end{tabular}

The reactor pressure vessel (RPV) is uninsulated to provide for decay heat removal under loss-of-forced-circulation conditions. In such events, heat is transported to the passive reactor cavity cooling system, which circulates outside air by natural circulation within enclosed panels surrounding the RPV. 


\section{Reference Core Design Description}

The core is designed to provide $350 \mathrm{MWt}$ at an average power density of $5.9 \mathrm{MW} / \mathrm{m}^{3}$. A core elevation view is shown in Figure A-1, and a plane view is shown in Figure A-2. The design of the core consists of an array of hexagonal fuel elements in a cylindrical arrangement surrounded by a single ring of identically sized solid graphite replaceable reflector elements, followed by a region of permanent reflector elements all located within an RPV. The core design parameters are shown in Table A-2.

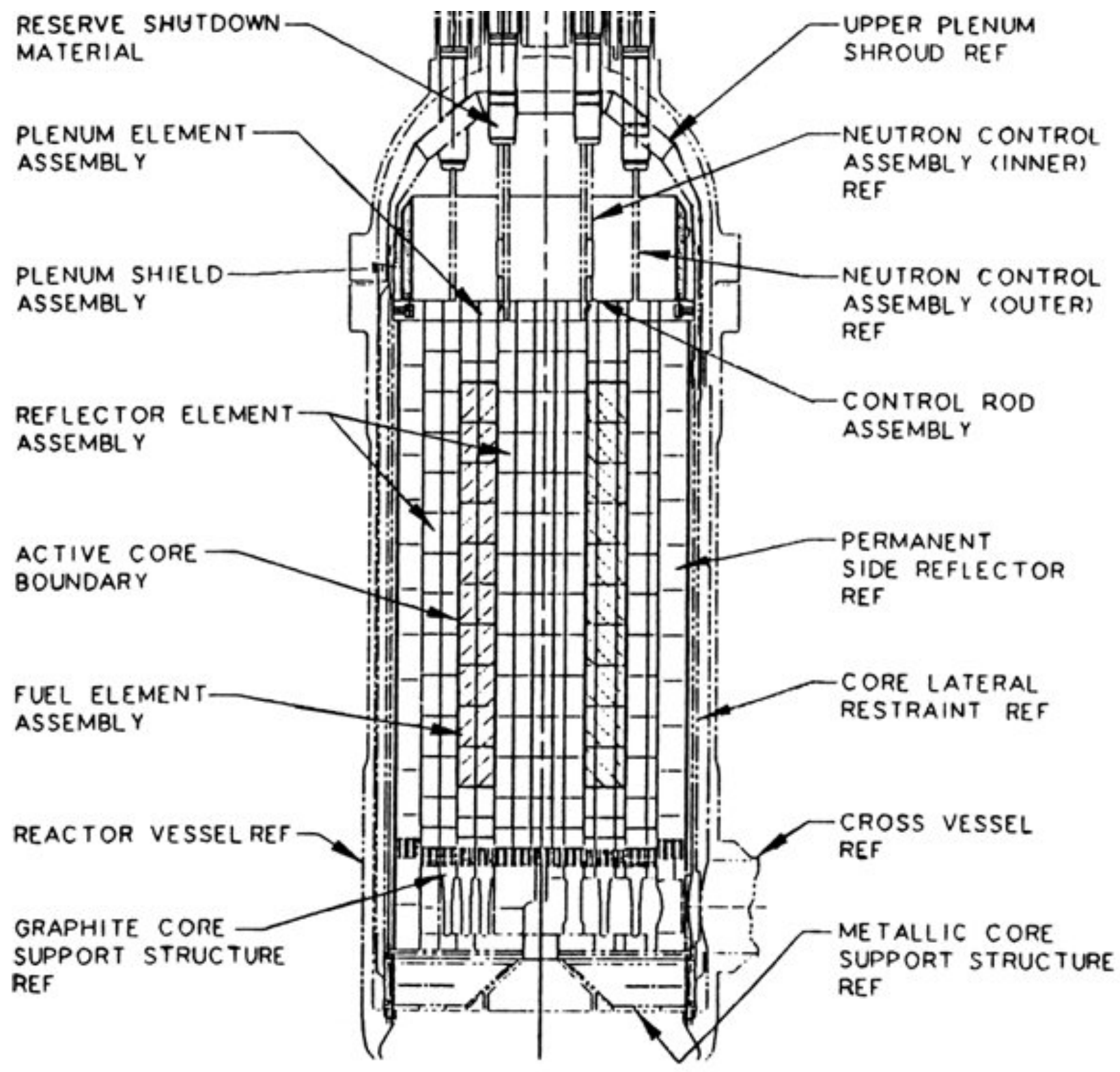

Figure A-1. MHTGR unit layout—axial (best available drawing). 


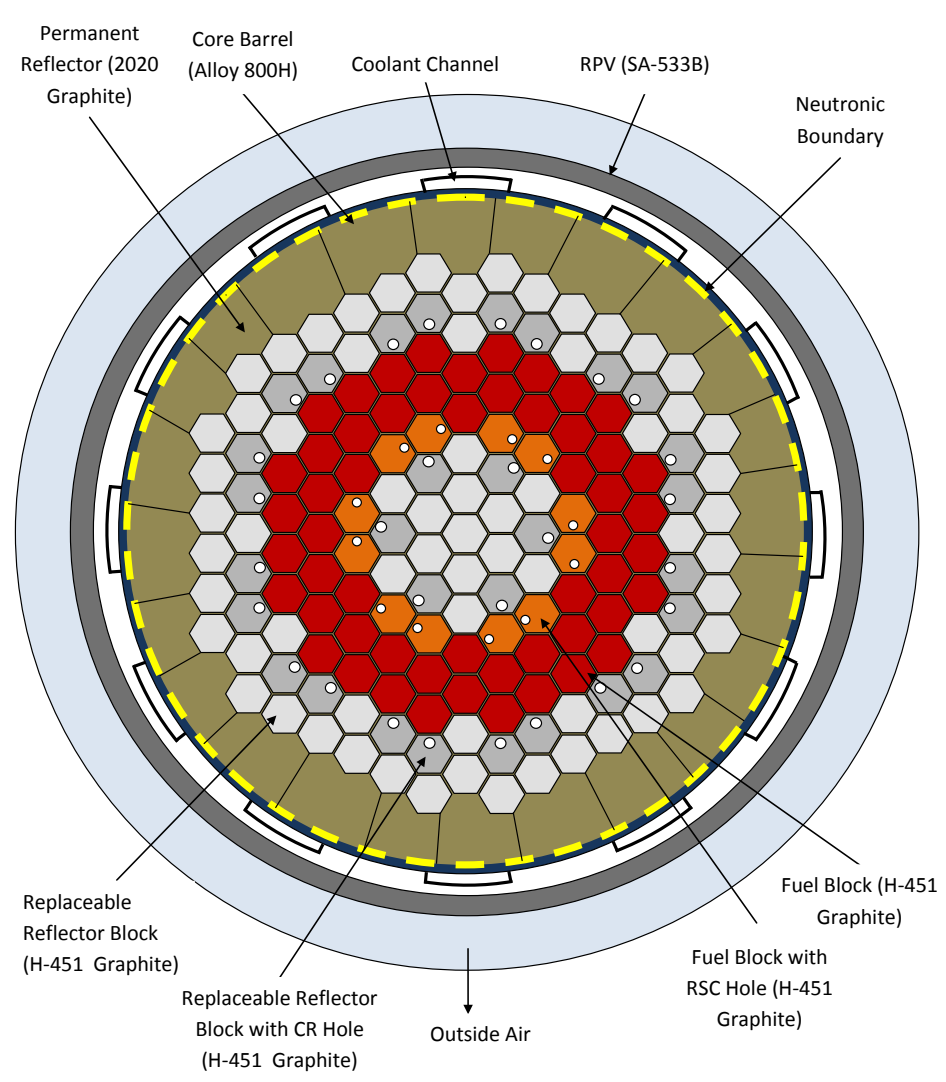

Figure A-2. MHTGR unit layout—plane.

Table A-2. Core design parameters.

\begin{tabular}{|l|c|c|}
\hline \multicolumn{1}{|c|}{ Core Parameter } & Value & Unit \\
\hline Thermal power & 350 & $\mathrm{MW}(\mathrm{t})$ \\
\hline Core power density & 5.93 & $\mathrm{MW} / \mathrm{m}^{3}$ \\
\hline Number of fuel columns & 66 & - \\
\hline Effective inner diameter of active core & 1.65 & $\mathrm{~m}$ \\
\hline Effective outer diameter of active core & 3.5 & $\mathrm{~m}$ \\
\hline Active core height & 7.93 & $\mathrm{~m}$ \\
\hline Number of fuel elements & - & - \\
\hline Standard elements & 540 & $10 / \mathrm{column}$ \\
\hline RSC elements & 120 & - \\
\hline Number of control rods & - & - \\
\hline Inner reflector & 6 & - \\
\hline Outer reflector & 24 & - \\
\hline Number of RSC channels in core & 12 & - \\
\hline Compacts per core (approximate) & $2.0358 \mathrm{E}+06$ & - \\
\hline Particles per core (approximate) & $1.2186 \mathrm{E}+10$ & - \\
\hline
\end{tabular}


The active core consists of hexagonal graphite fuel elements containing blind holes for fuel compacts and full-length channels for helium coolant flow. The fuel elements are stacked to form columns (10 fuel elements per column) that rest on support structures. The active core columns form a three-row annulus with columns of hexagonal graphite reflector elements in the inner and outer regions. Thirty reflector columns contain channels for control rods and twelve columns in the core also contain channels for the reserve shutdown material (RSS).

The active core effective outer diameter of $3.5 \mathrm{~m}$ is sized to maintain a minimum reflector thickness of $1 \mathrm{~m}$ within the $6.55-\mathrm{m}$ inner diameter reactor vessel. The height of the core with 10 elements in each column is $7.9 \mathrm{~m}$, which allows maximum power rating and axial power stability over the cycle.

The core reactivity is controlled by a combination of lumped burnable poison (LBP), movable poison, and a negative temperature coefficient. This fixed poison is in the form of LBP compacts; the movable poison is in the form of metal clad control rods. Should the control rods become inoperable, a backup reserve shutdown control (RSC) is provided in the form of borated pellets that may be released into channels in the active core.

The control rods are fabricated from natural boron in annular graphite compacts with metal cladding for structural support. The control rods are located in the outer ring of the inner reflector and the inner ring of the outer reflector (see Figure A-2). These control rods enter the reflector through the top reactor vessel penetrations in which the control rod drives are housed. The 24 control rods located in the outer reflector are the operating control rods, and are used for control during power operation and for reactor trip. The six control rods in the inner reflector are the startup control rods, which are withdrawn before the reactor reaches criticality.

\section{Fuel Element Design}

There are two types of fuel elements, a standard element (see Figure A-3) and a reserve shutdown element (see Figure A-4) that contains a channel for RSC. The fuel elements are right hexagonal prisms of the same size and shape as the Fort St. Vrain high-temperature gas-cooled reactor elements. The fuel element design description is shown in Table A-3. The fuel and coolant holes are located in parallel through the length of the element. The standard fuel element contains a continuous array of fuel and coolant holes in a regular triangular array of two fuel holes per one coolant hole. The six corner holes contain LBP compacts. 

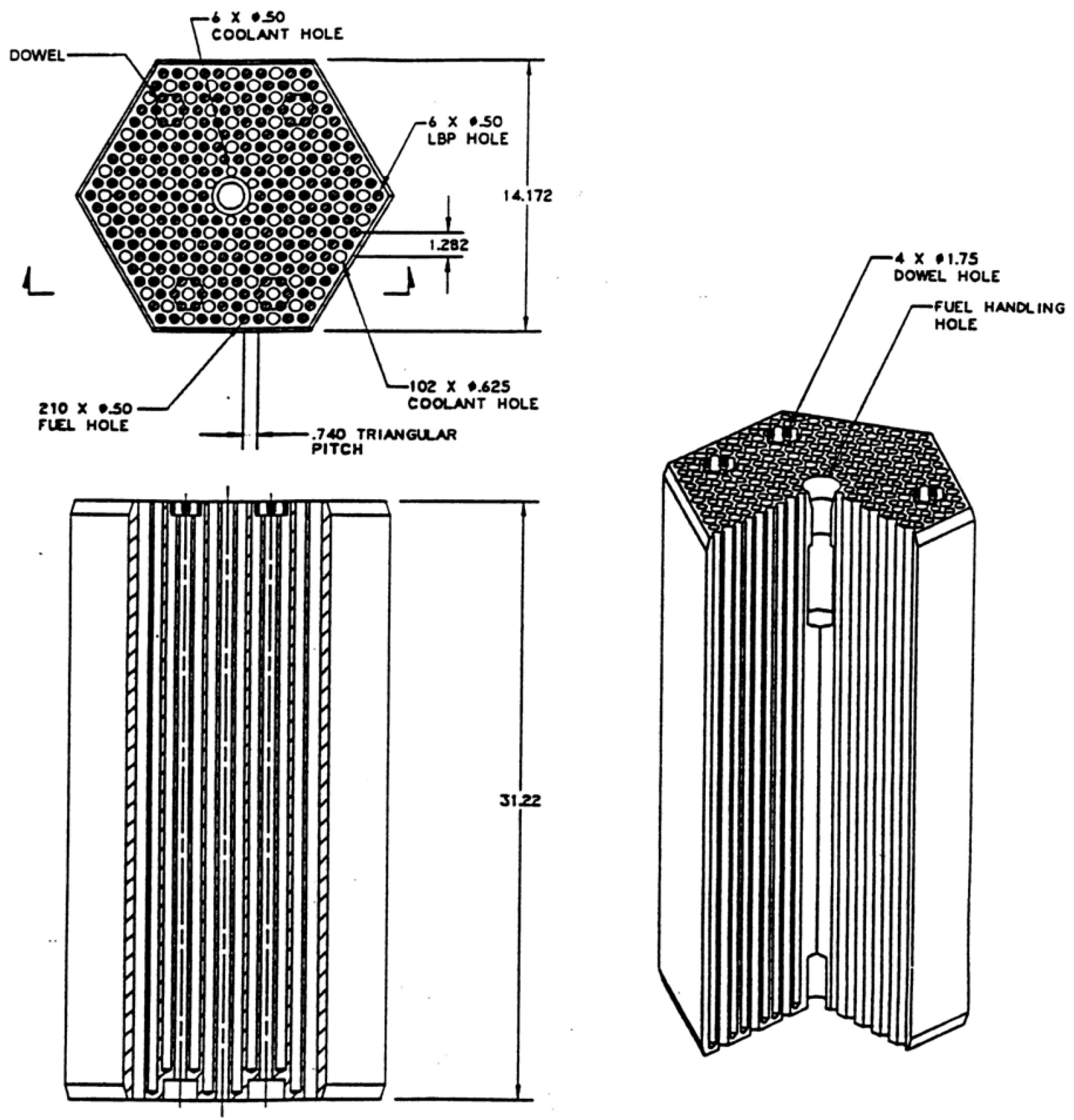

Figure A-3. Standard fuel element (units in inches) (best available drawing). 


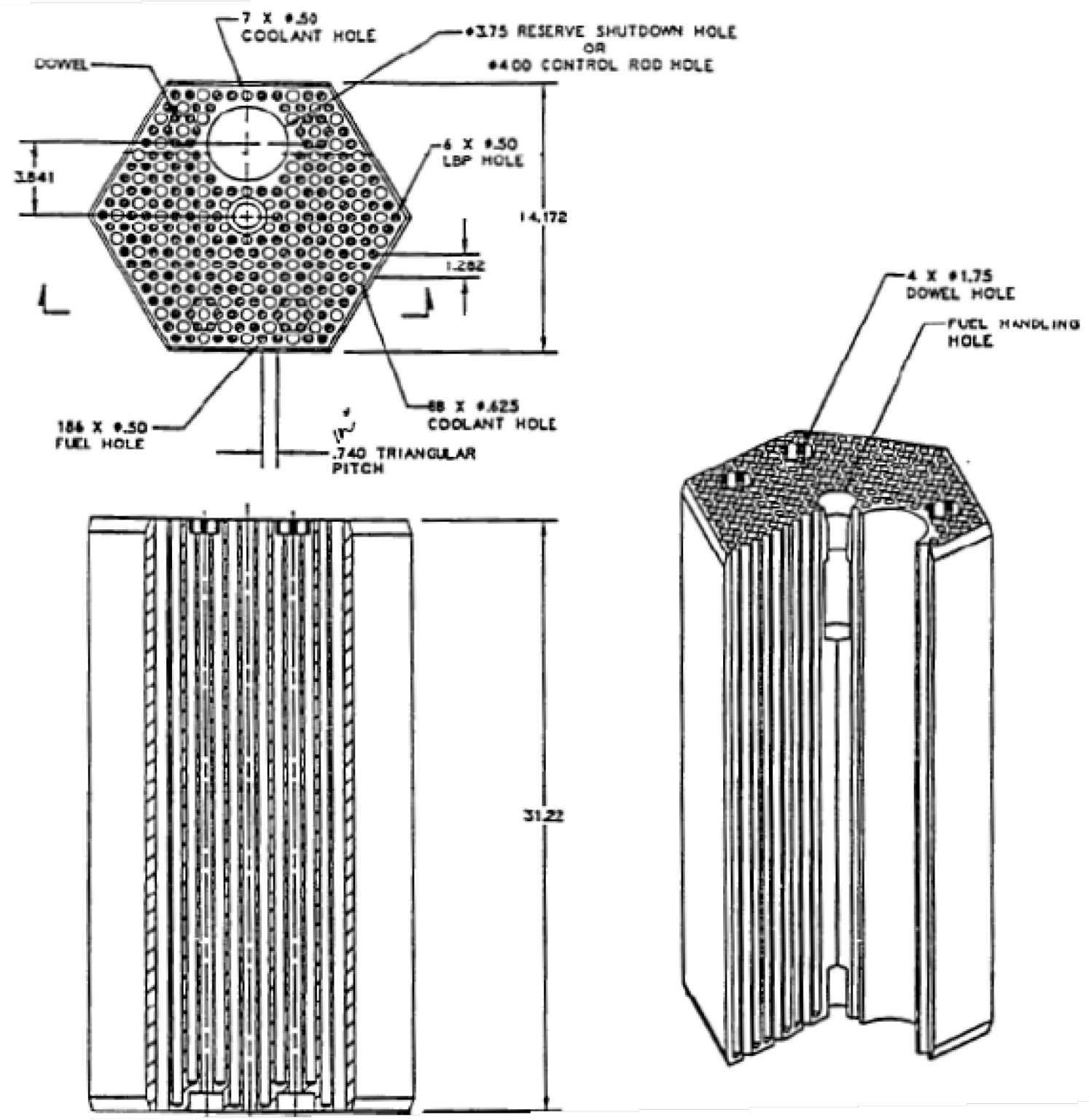

Figure A-4. RSC fuel element (units in inches) (best available drawing). 
Table A-3. Fuel element description.

\begin{tabular}{|l|c|c|}
\hline \multicolumn{1}{|c|}{ Fuel Element Geometry } & Value & Unit \\
\hline Block graphite density (for lattice calculations) & 1.85 & $\mathrm{~g} / \mathrm{cm}^{3}$ \\
\hline Fuel holes per element & - & - \\
\hline \multicolumn{1}{|c|}{ Standard element } & 210 & - \\
\hline RSC element & 186 & $\mathrm{~cm}$ \\
\hline Fuel hole radius & 0.635 & - \\
\hline Coolant holes per element (large/small) & - & - \\
\hline \multicolumn{1}{|c|}{ Standard element } & $102 / 6$ & - \\
\hline \multicolumn{1}{|c|}{ RSC element } & $88 / 7$ & $\mathrm{~cm}$ \\
\hline Large coolant hole radius & 0.794 & $\mathrm{~cm}$ \\
\hline Small coolant hole radius & 0.635 & $\mathrm{~cm}$ \\
\hline Fuel/coolant pitch & 1.8796 & $\mathrm{~cm}$ \\
\hline Block pitch & 36 & $\mathrm{~cm}$ \\
\hline Element length & 79.3 & $\mathrm{~cm}$ \\
\hline Fuel handling diameter & 3.5 & $\mathrm{~cm}$ \\
\hline Fuel handling length & 26.4 & $\mathrm{~cm}$ \\
\hline RSC hole diameter & 9.525 & - \\
\hline LBP holes per element & 6 & $\mathrm{~cm}$ \\
\hline LBP radius & 0.5715 & $\mathrm{~cm}$ \\
\hline LBP gap radius & 0.635 & - \\
\hline
\end{tabular}

\section{Fuel Particle and Compact Design}

The fuel is comprised of TRISO fuel particles bonded in a graphite matrix to form a cylindrical compact. The compacts are then inserted into hexagonal graphite blocks to construct a fuel element. TRISO particles consist of various layers acting in concert to provide a containment structure that limits radioactive product release. They include a fuel kernel, porous carbon layer, inner pyrolitic carbon (IPyC), silicon carbide (SiC), and outer pyrolitic carbon (OPyC). Details of the TRISO particle and compact designs are given in Table A-4. These specifications are different from the initial General Atomics design that used a dual-particle design. 
Table A-4. TRISO/fuel compact description.

\begin{tabular}{|c|c|c|}
\hline $\begin{array}{c}\text { TRISO Fuel Element } \\
\text { (General Design Parameters for Lattice Calculations) }\end{array}$ & Value & Unit \\
\hline Fissile material & $\mathrm{UC}_{0.5} \mathrm{O}_{1.5}$ & - \\
\hline Enrichment $\left({ }^{235} \mathrm{U}\right.$ average $)$ & 15.5 & $\mathrm{w} / \mathrm{o}$ \\
\hline Radii & - & - \\
\hline Kernel & 0.02125 & $\mathrm{~cm}$ \\
\hline Buffer & 0.03125 & $\mathrm{~cm}$ \\
\hline IPyC & 0.03475 & $\mathrm{~cm}$ \\
\hline $\mathrm{SiC}$ & 0.03825 & $\mathrm{~cm}$ \\
\hline $\mathrm{OPyC}$ & 0.04225 & $\mathrm{~cm}$ \\
\hline Densities & - & - \\
\hline Kernel & 10.5 & $\mathrm{~g} / \mathrm{cm}^{3}$ \\
\hline Buffer & 1.0 & $\mathrm{~g} / \mathrm{cm}^{3}$ \\
\hline $\mathrm{IPyC}$ & 1.9 & $\mathrm{~g} / \mathrm{cm}^{3}$ \\
\hline $\mathrm{SiC}$ & 3.2 & $\mathrm{~g} / \mathrm{cm}^{3}$ \\
\hline $\mathrm{OPyC}$ & 1.9 & $\mathrm{~g} / \mathrm{cm}^{3}$ \\
\hline Packing fraction (average) & 0.350 & - \\
\hline Compact radius & 0.6225 & $\mathrm{~cm}$ \\
\hline Compact gap radius & 0.635 & $\mathrm{~cm}$ \\
\hline Compact length & 4.928 & $\mathrm{~cm}$ \\
\hline
\end{tabular}

\section{Lumped Burnable Poison Design}

The LBP consists of boron carbide $\left(\mathrm{B}_{4} \mathrm{C}\right)$ granules dispersed in graphite compacts. The $\mathrm{B}_{4} \mathrm{C}$ granules are pyrolitic carbon $(\mathrm{PyC})$ coated to limit oxidation and loss from the system. The amount of burnable poison is determined by reactivity control requirements, which may vary with each reload cycle. For the Coordinated Research Project specification, only the fresh fuel blocks contain the LBPs, since it is assumed the B-10 content of the LBPs in the depleted fuel block has been sufficiently reduced that it can be neglected. The current design also uses a constant LBP compact diameter of $1.143 \mathrm{~cm}$ for all cycles. Details of the LBP design are given in Table A-5. 
Table A-5. LBP description.

\begin{tabular}{|c|c|c|c|c|}
\hline LBP holes per element & \multicolumn{4}{|c|}{6} \\
\hline LBP compacts per LBP rod & \multicolumn{4}{|c|}{14} \\
\hline Compact diameter $(\mathrm{cm})$ & \multicolumn{4}{|c|}{1.143} \\
\hline Compact length $(\mathrm{cm})$ & \multicolumn{4}{|c|}{5.156} \\
\hline Rod length $(\mathrm{cm})$ & \multicolumn{4}{|c|}{72.187} \\
\hline Volume fraction of $\mathrm{B}_{4} \mathrm{C}$ particles & \multicolumn{4}{|c|}{0.109} \\
\hline $\begin{array}{c}\text { Lumped Burnable Poison (FBP) } \\
\text { Component }\end{array}$ & Composition & $\begin{array}{c}\text { Diameter } \\
(\mu \mathrm{m})\end{array}$ & $\begin{array}{c}\text { Thickness } \\
(\mu \mathrm{m})\end{array}$ & $\begin{array}{l}\text { Density } \\
\left(\mathrm{g} / \mathrm{cm}^{3}\right)\end{array}$ \\
\hline $\mathrm{B}_{4} \mathrm{C}$ particle & - & - & - & - \\
\hline Kernel & $\mathrm{B}_{4} \mathrm{C}$ & 200 & - & 2.47 \\
\hline Buffer coating & Graphite & - & 18 & 1.0 \\
\hline Pyrolitic coating & Graphite & - & 23 & 1.87 \\
\hline Matrix & Graphite & - & - & 0.94 \\
\hline
\end{tabular}

\section{Replaceable Reflector Design}

The replaceable reflector elements are graphite blocks of the same shape, size, and material as the fuel elements. The top and bottom reflector elements contain coolant holes to match those in the active core. All reflector elements have dowel connections for alignment (see Figure A-5).

The reflector above the active core is composed of two layers: one layer of full-height elements above a layer of half-height elements, for total reflector height of $1.2 \mathrm{~m}$. The top reflector elements channel coolant flow to the active core and provide for insertion of RSS into the active core. They have the same array of coolant holes as the fuel element and the same holes for insertion of reactivity control devices.

The reflector below the active core has a total height of $1.6 \mathrm{~m}$. It consists of two layers: one layer of two half-height reflector elements above a layer of two half-height flow distribution and support elements. The bottom two elements provide for the passage of coolant from the active core into the core support area. This is accomplished by directing the coolant channel flow to the outside of the core support pedestal. The channels for the control rods and RSS stop at the top of the lower reflector so that neither the rods nor the RSS material can exit the core at the bottom. However, small holes are drilled through the reflector below the control rod channels so that adequate cooling is provided for the rods when they are inserted in the core or side reflectors without excessive coolant flow through these channels when the rods are withdrawn from the core.

The outer side reflector includes one full row and a partial second row of hexagonal reflector columns. The outer row of hexagonal elements is solid, with the exception of the handling holes. Twenty-four of the elements in the inner row of the outer side reflector also have a control rod channel as shown in Figure A-2. The control rod channel has a diameter of $10.2 \mathrm{~cm}$ until the bottom reflector assembly and narrows down to $2.5 \mathrm{~cm}$. Crushable graphite matrix at the lower end of each control rod channel will limit the load between the control rod assembly and reflector element in the event that the neutron control assembly support fails. The control rod channel is centered on the flat nearest the active core $9.76 \mathrm{~cm}$ from the center of the reflector element. The distance from the flat of the reflector block to the edge of the control rod channel is $2.7 \mathrm{~cm}$. 


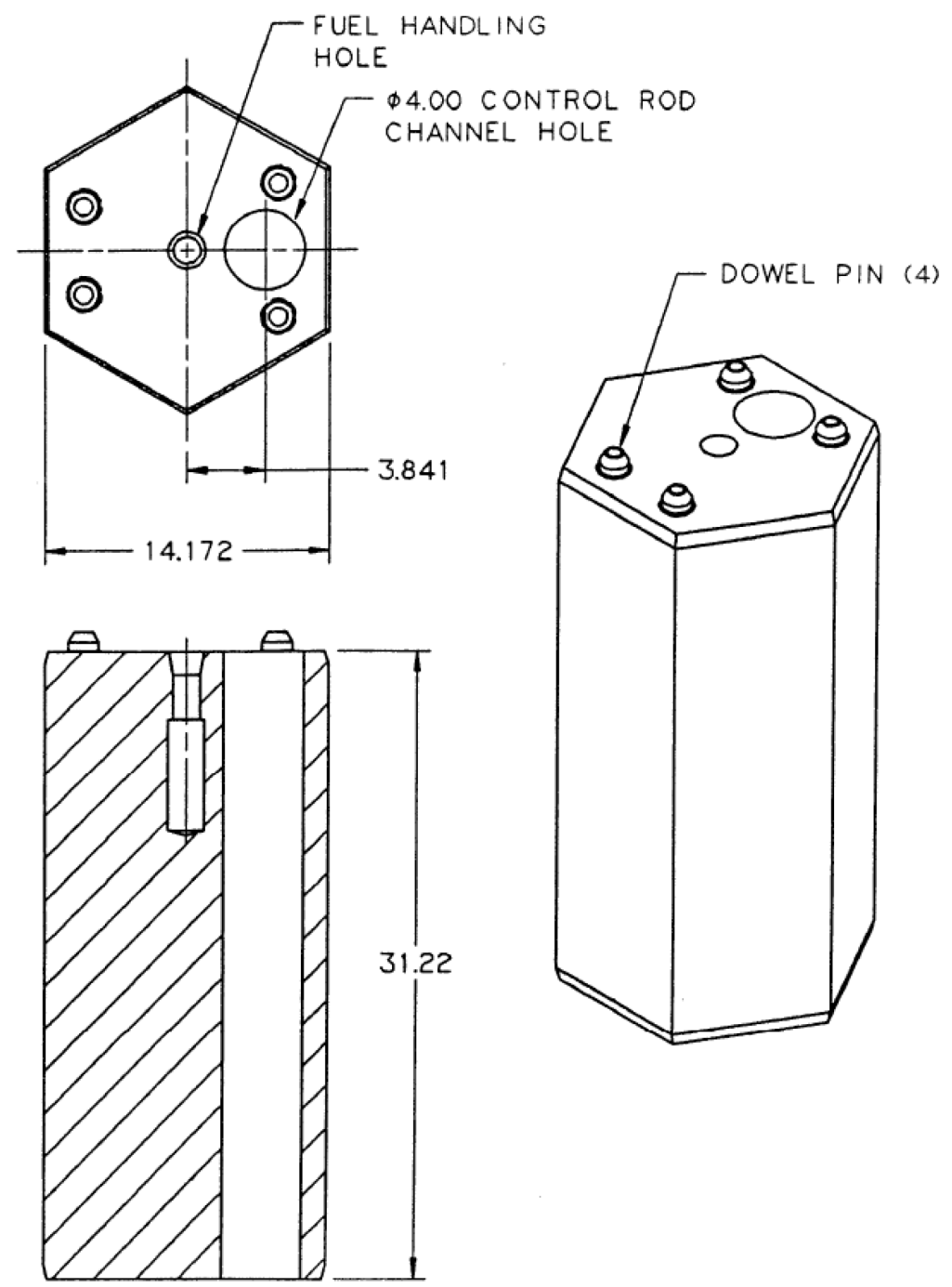

Figure A-5. Hexagonal reflector element with control rod hole (units in inches) (best available drawing).

The inner (central) reflector includes 19 columns of hexagonal elements. The central and side reflector columns consist of, from top down, one three-quarter-height element, eleven full-height elements, one three-quarter-height element, and two half-height elements, above the core support pedestal. The total reflector height for the equivalent 13.5 elements above the top of the core support pedestal is $10.7 \mathrm{~m}$. The dowel/socket connection at each axial element-to-element interface provides alignment for refueling and control rod channels, and transfers seismic loads from reflector elements. There are six control blocks in the inner reflector.

\section{Control Rods and Reserve Shutdown Control}

The control rod design used in the MHTGR is shown in Figure A-6. The neutron absorber material consists of $\mathrm{B}_{4} \mathrm{C}$ granules uniformly dispersed in a graphite matrix and formed into annular compacts. The boron is enriched to $90 \mathrm{wt} \% \mathrm{~B}-10$ and the compacts contain $40 \mathrm{wt} \% \mathrm{~B}_{4} \mathrm{C}$. The compacts have an inner diameter of $52.8 \mathrm{~mm}$, an outer diameter of $82.6 \mathrm{~mm}$, and are enclosed in Incoloy $800 \mathrm{H}$ canisters for structural support. Alternatively, carbon-fiber reinforced carbon composite canisters, or SiC, may be used for structural support. The control rod consists of a string of 18 canisters with sufficient mechanical flexibility to accommodate any postulated offset between elements, even during a seismic event. 

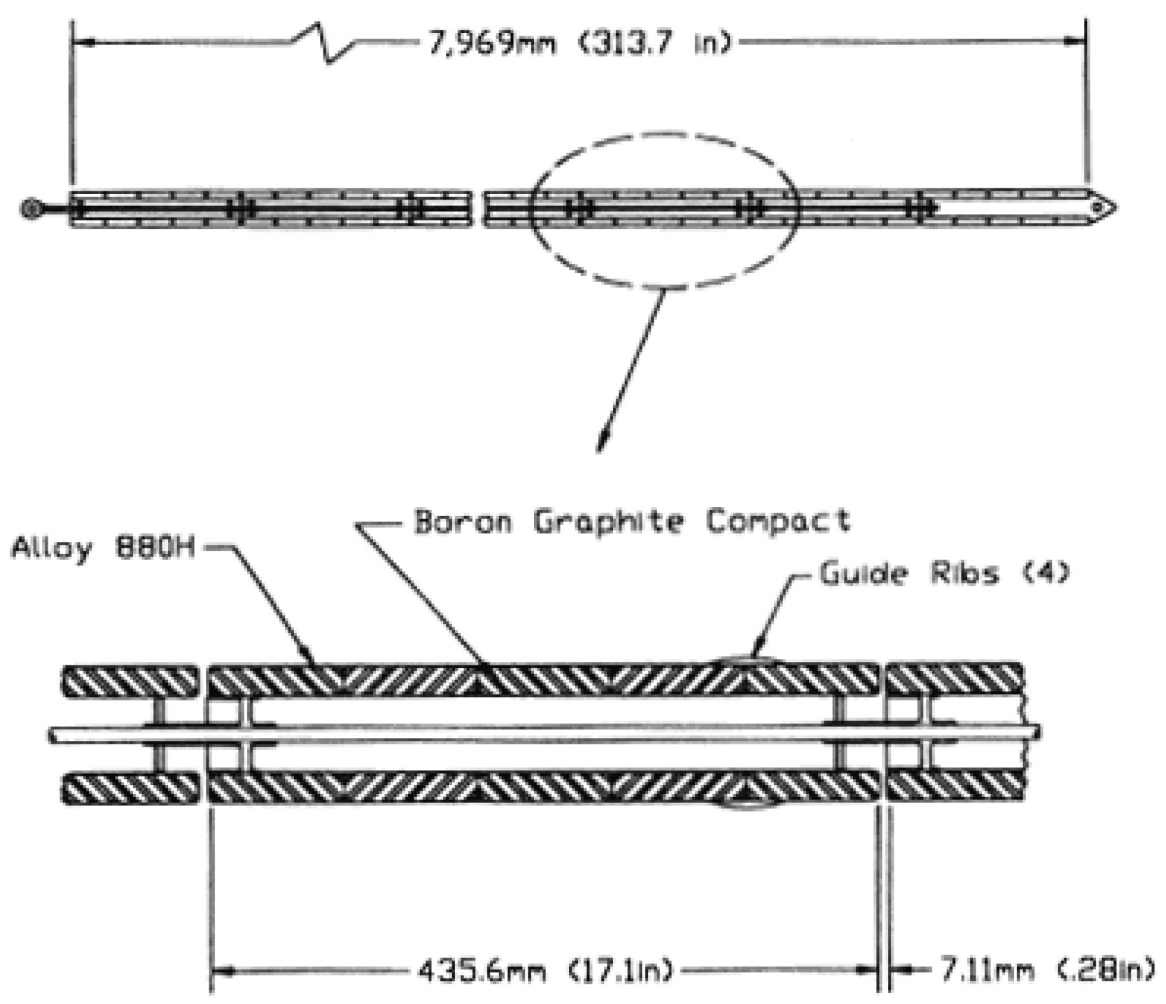

Figure A-6. Control rod design (best available drawing).

The RSC material consists of $40 \mathrm{wt} \%$ natural boron in $\mathrm{B}_{4} \mathrm{C}$ granules dispersed in a graphite matrix and formed into pellets. The $\mathrm{B}_{4} \mathrm{C}$ granules are coated with $\mathrm{PyC}$ to limit oxidation and loss from the system during high-temperature, high-moisture events. When released into the reserve shutdown channel in the fuel element, the pellets have a packing fraction of $\geq 0.55$.

The control rods are withdrawn in groups with three control rods in each group. These three control rods are symmetrically located around the core, so that one rod is located in each 120-degree sector of the core. During normal power operation, control is accomplished with only the operating control rods (the startup control rods are in the fully withdrawn position).

\section{Permanent Reflector Design}

The permanent reflector provides the transition from the hexagonal core to the cylindrical core boundary (Figure A-2). Neutron shielding of the reactor structural equipment consists of graphite permanent reflector elements containing a $10-\mathrm{cm}$-thick borated region at the outer boundary, adjacent to the core barrel. This borated region is not modeled in the benchmark.

\section{Reactor and Core Structure Geometry and Dimensions}

The benchmark reactor unit geometry definition is given in this section. Figure A-7 and Figure A-8 show the general layout of the reactor. The dimensions of the key components are included in Figure A-9 and Figure A-10. The origin for the radial dimension is set at the center of the core axis. The origin for the axial dimension is set at the bottom of the RPV. The origin for the azimuthal dimension is set at the 120-degree symmetry line shown in Figure A-7 and moves clockwise. Note that the distance specified below the active core region includes the bottom reflectors and the graphite core support structure. 


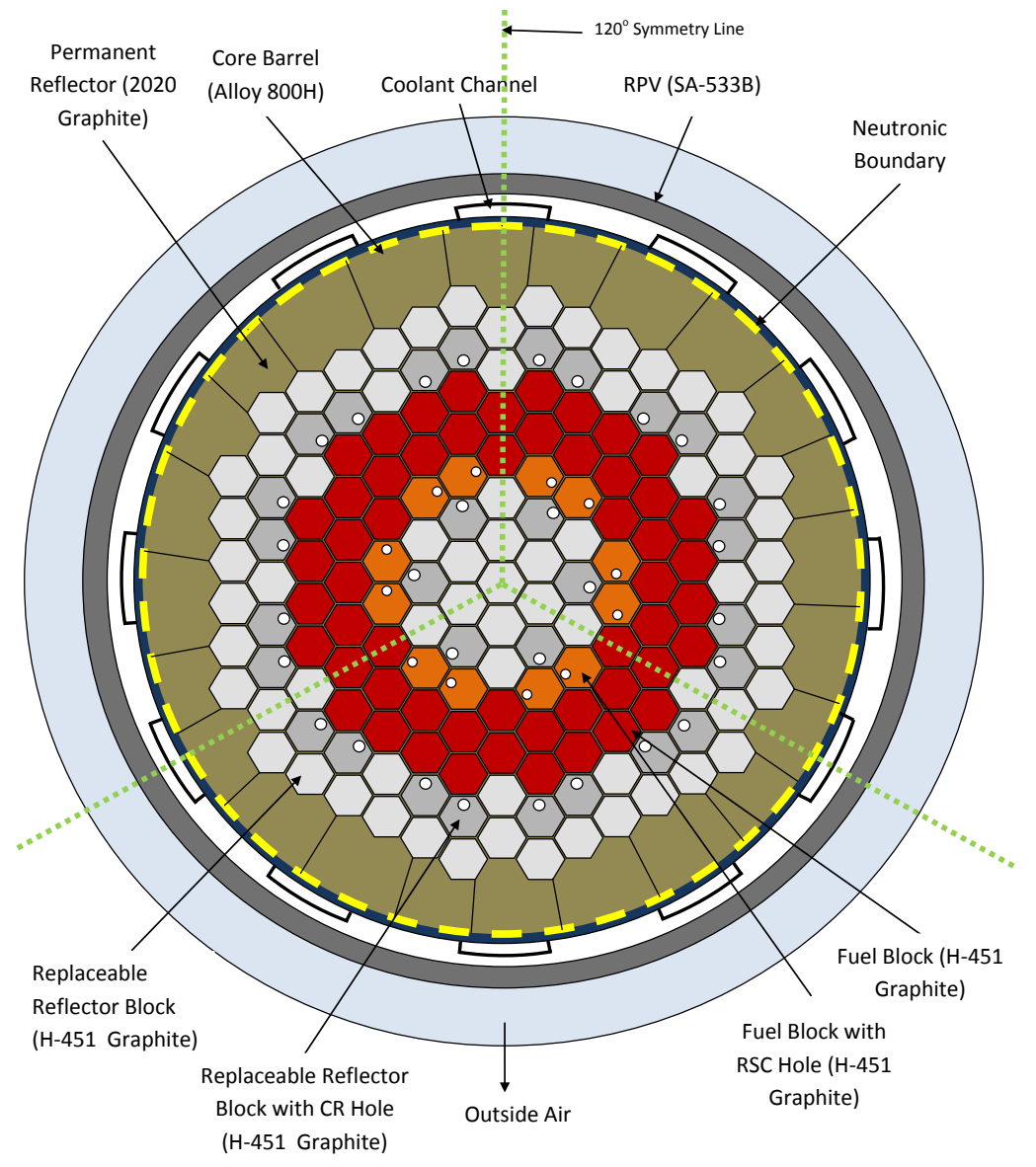

Figure A-7. Core radial layout. 


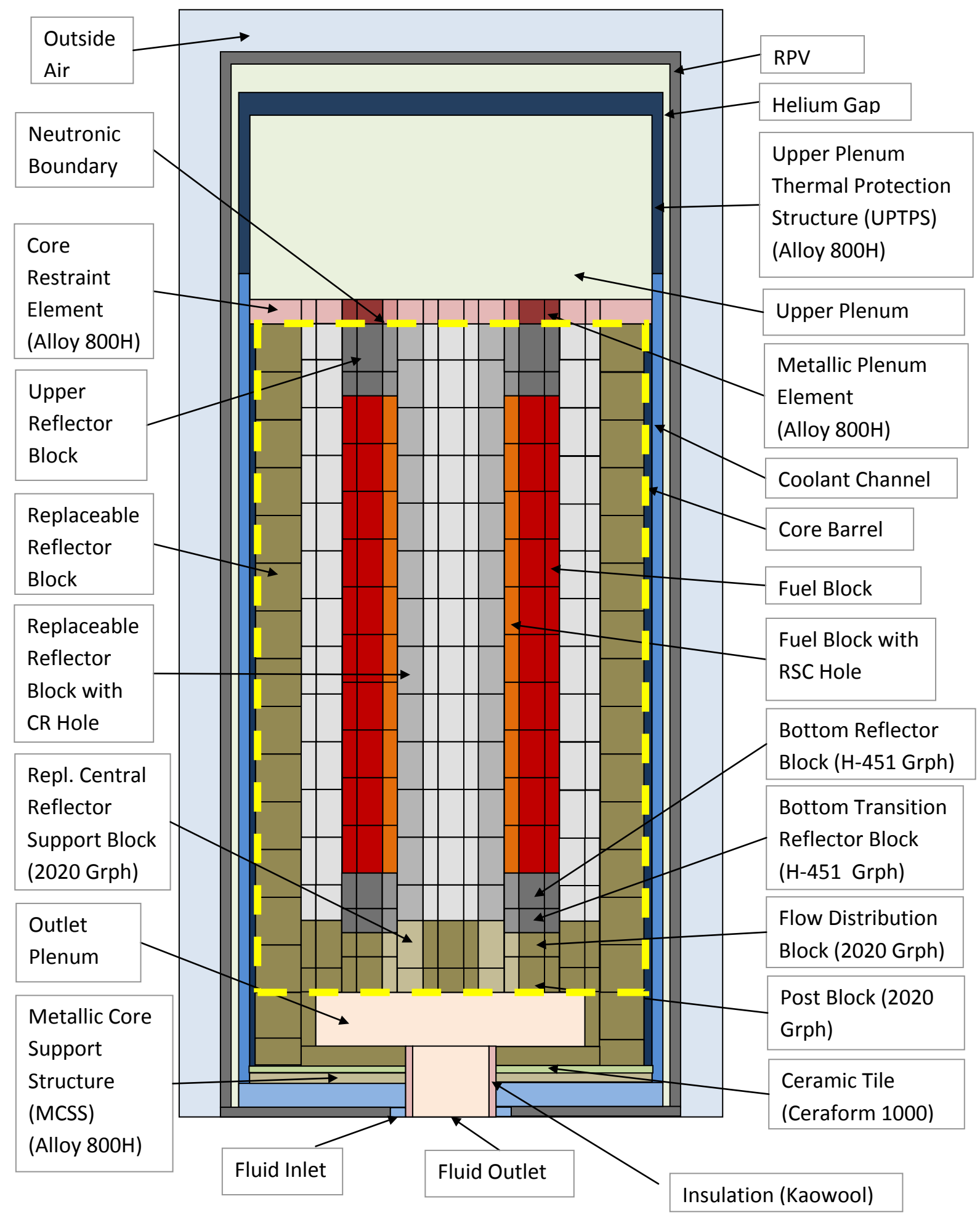

Figure A-8. Core axial layout. 


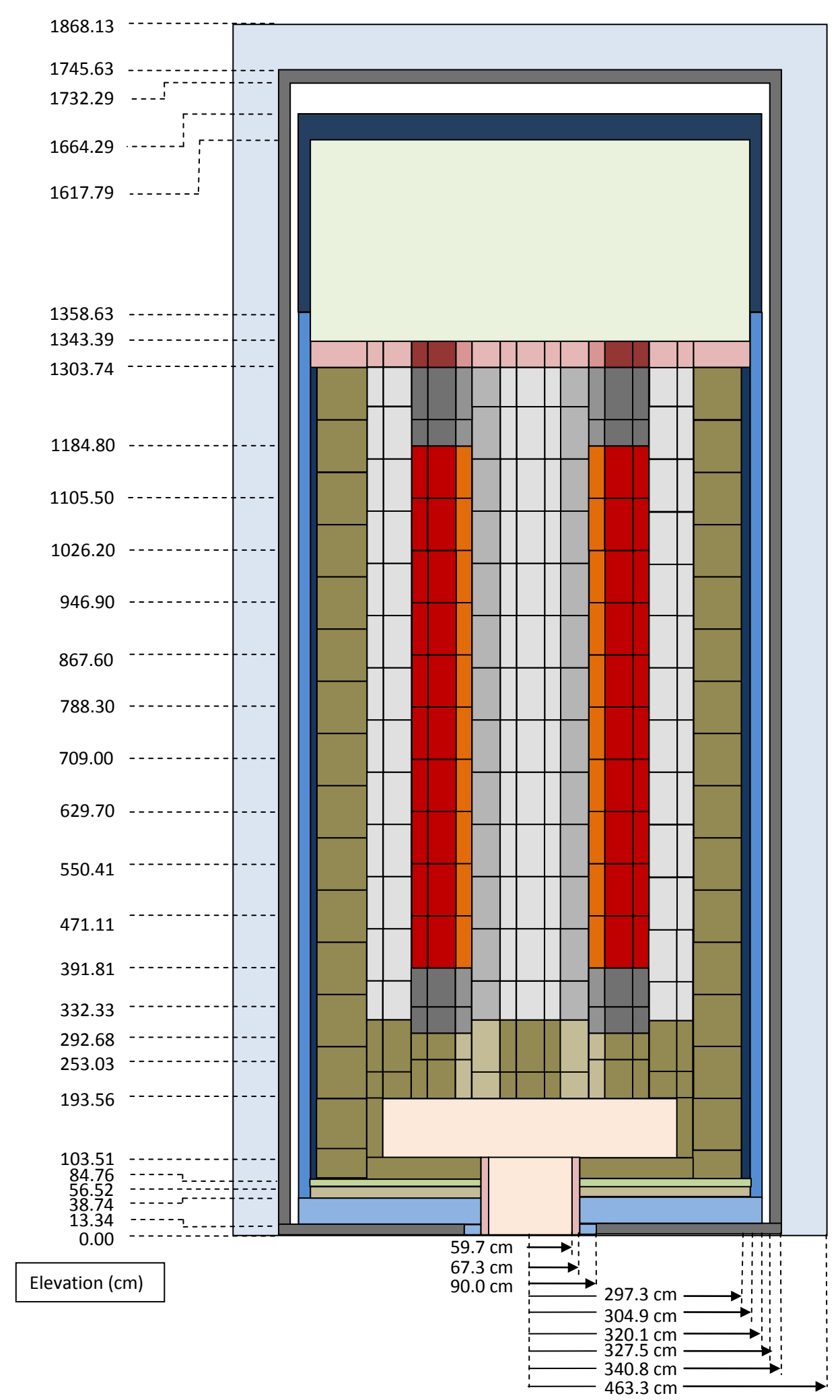

Figure A-9. Core axial dimensions. 


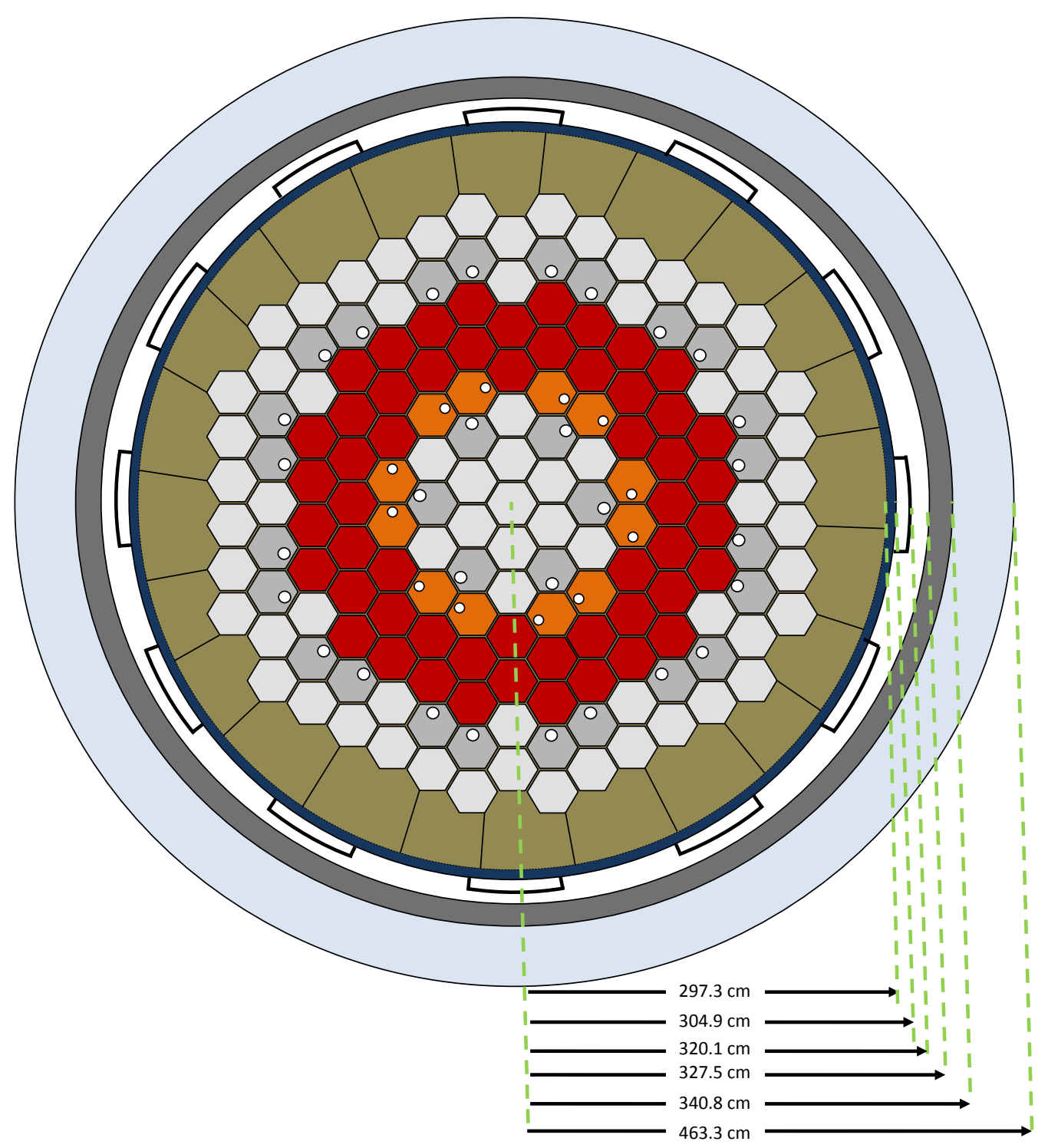

Figure A-10. Core radial dimensions.

\section{Neutronic Definition}

The axial neutronic mesh extends from the top reflector and core restraint element interface (1303.74 cm in Figure A-9) to the graphite core support structure (just above the outlet plenum at $193.56 \mathrm{~cm})$. Radially the inner radius of the core barrel $(297.3 \mathrm{~cm}$ in Figure A-10) forms the outer boundary. Figure A-11 shows the whole core region numbering for the one-third core. The bottom reflector is defined as Layer 1. Radially the central column is Column 1, the rest of the numbering follows the various radial rings up to 91 columns. The mixed core fuel loading pattern is shown in Figure A-12. 


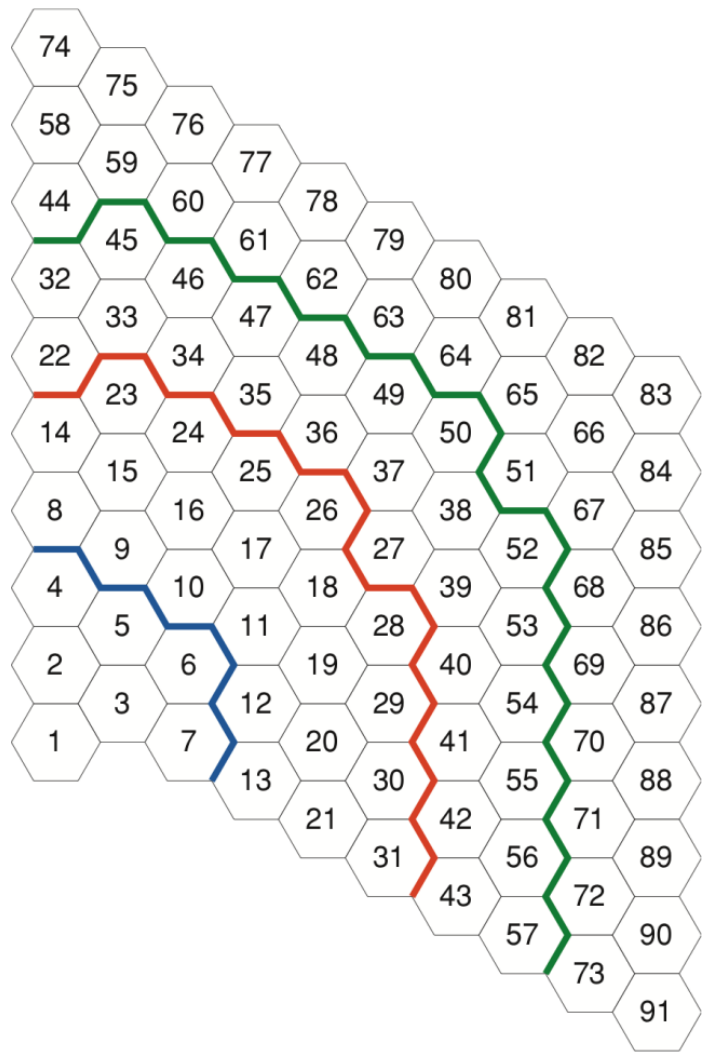

Figure A-11. "Whole core" numbering layout (Layer 1).

NOTE: $\quad$ Blocks 44 and 51 are part of the permanent reflector region and Blocks 22 and 27 are part of the replaceable reflector region.

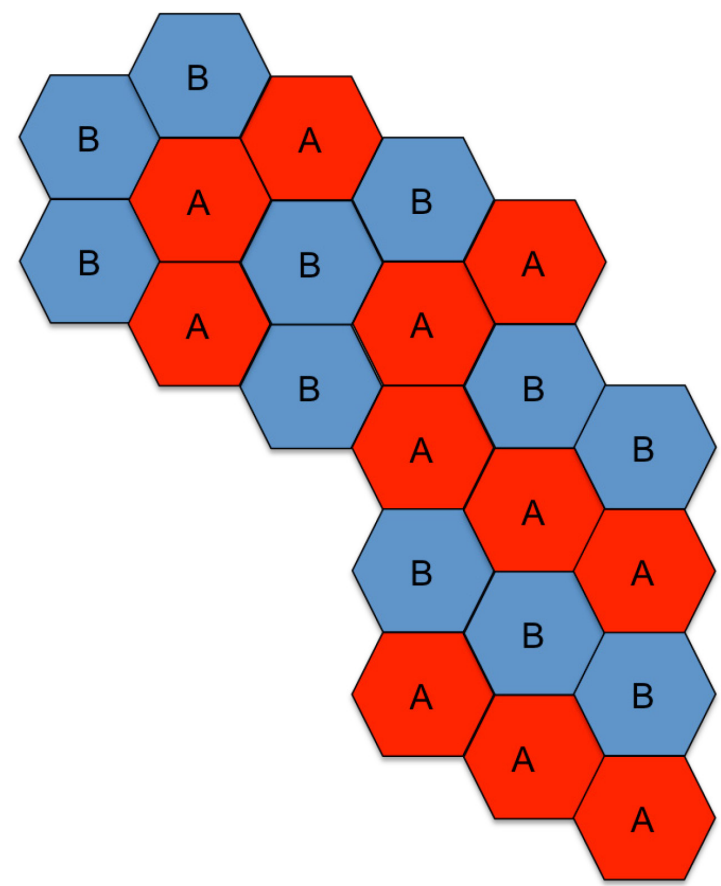

Figure A-12. Mixed core loading pattern: fresh (A) and depleted (B) fuel. 


\section{Neutronic Simplifications}

The following simplifications are assumed for the neutronic definition:

- The core is one-third symmetric as far as the cross-section specification is concerned

- The participants should assume for the neutronics solution that the empty control rod penetrations in the reflector regions contain graphite

- Neutron streaming in the gaps, coolant holes, and control holes is ignored

- Axial dimensions of the fuel rod are simplified: the length of the fuel rods and lumped burnable poison (FBP) are assumed to be the full height of the block, the fuel handling holes are replaced with graphite, and the axial details of the control rods are ignored

- Element bowing due to temperature gradients is ignored.

\section{Neutronic Boundary Conditions}

The boundary conditions that need to be imposed on the neutronic domain are shown in Table A-6.

Table A-6. Neutronic boundary conditions.

\begin{tabular}{|l|c|l|}
\hline \multicolumn{1}{|c|}{ Description } & $\begin{array}{c}\text { Position } \\
(\mathrm{cm})\end{array}$ & \multicolumn{1}{c|}{$\begin{array}{c}\text { Boundary Condition (BC) } \\
\text { Type }\end{array}$} \\
\hline Outer boundary (inner radius of core barrel) & 297.30 & Non-re-entrant current/vacuum \\
\hline Below upper core restraint element & 1303.74 & Non-re-entrant current/vacuum \\
\hline Below graphite core support structure & 193.56 & Non-re-entrant current/vacuum \\
\hline Core segment sides & (one-third core segment) & Periodic \\
\hline
\end{tabular}

\section{REFERENCE}

[1] Ortensi, J., et al. "Benchmark of the Modular High-Temperature Gas-Cooled Reactor 350 MW Core Design," Volumes I and II, NEA/NSC/R(2017)4, February 2018. 


\section{Appendix B}

\section{Phase II Output Reporting}




\section{Appendix B}

\section{Phase II Output Reporting}

\section{Exercises II-1a/b}

The output data requested from the participants for comparison of the data sets is specified in the embedded template Excel file (Figure B-1). Based on the preliminary burnup calculations performed at Idaho National Laboratory, 41 burn steps are recommended (Table B-1). The power density required to calculate the flux level is taken as $65.9 \mathrm{MW} / \mathrm{MTHM}$. The 41 burnup steps ensure a proper nuclide inventory prediction and consequently an appropriate flux spectrum during the cycle, which is a critical element of the uncertainty quantification.

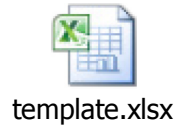

Figure B-1. Excel file: submission template for Exercises II-1a/b.

Table B-1. Exercises II-1a/b required burn steps.

\begin{tabular}{|c|c|c|}
\hline Burn Step (d) & Cumulative Time (d) & $\begin{array}{c}\text { Cumulative Burnup } \\
\text { (MWd/MTHM) }\end{array}$ \\
\hline 3.03 & 3.03 & 200 \\
\hline 4.55 & 7.58 & 500 \\
\hline 22.76 & 30.34 & 2000 \\
\hline 30.35 & 60.69 & 4000 \\
\hline 30.35 & 91.04 & 6000 \\
\hline \multicolumn{2}{|c|}{35 additional equal steps of 30.35 days each } \\
\hline 30.35 & 1153.26 & 76000 \\
\hline
\end{tabular}

Participants are requested to provide information at four of the 41 burn steps:

- $\quad 0 \mathrm{GWd} / \mathrm{MTU}$ : fresh fuel

- $\quad 0.15 \mathrm{GWd} / \mathrm{MTU}$ : during xenon buildup (corresponding to 2.27 days of hot full power operation)

- $40 \mathrm{GWd} / \mathrm{MTU}$ : middle of cycle

- $80 \mathrm{GWd} / \mathrm{MTU}$ : end of cycle.

At the beginning of the cycle, no nuclide data is required since the actinide inventory is given as an input and no fission products have built up yet. At the second time point $(0.15 \mathrm{GWd} / \mathrm{MTU})$, the fission product buildup, plutonium buildup, uranium depletion, and boron depletion are considered to be sufficiently small and hence are not required for submission. Thus, only the ${ }^{135} \mathrm{Xe},{ }^{135} \mathrm{I},{ }^{149} \mathrm{Sm}$, and ${ }^{151} \mathrm{Sm}$ are requested. The samarium uncertainty and concentration may be very small compared to its steady-state concentration at this time step. 
The middle and end of cycle templates are identical. The nuclide inventory required for the last two steps (e.g., $40 \mathrm{GWd} / \mathrm{MTU}$ and $80 \mathrm{GWd} / \mathrm{MTU}$ ) includes the uranium and plutonium actinides, in addition to a few minor actinides. The fission product list consists of the same set of fission products required by the Light-Water Reactor Uncertainty Analysis in Modeling benchmark, with the following additional isotopes of interest to high-temperature gas-cooled reactors:

- $\quad{ }^{135} \mathrm{Xe}$ and ${ }^{135} \mathrm{I}$, in order to obtain uncertainty information on the xenon concentration and the progenitor

- ${ }^{10} \mathrm{~B}$ used as burnable poison

- $107,110 \mathrm{~m}, 111 \mathrm{Ag}$ due to the high diffusion coefficient of silver (especially ${ }^{110 \mathrm{~m}} \mathrm{Ag}$ ) within the TRISO particles during transients

- $102,104,105,106,107,108,110 \mathrm{Pd}$ due to its high diffusion coefficient through the TRISO particles.

The nuclide inventory list is quite extensive at this point, and subject to modification after feedback from the participants. Feedback is also requested on the importance of the one-group cross sections and reaction rates for these depletion exercises, since the major figure of merit is the uncertainty of the eigenvalue and isotope concentrations.

\section{Exercises II-2a/b}

Participants are requested to provide the following parameters for comparison of Exercises II- $2 \mathrm{a} / \mathrm{b}$ :

- Eiegenvalue (keff) and standard deviation due to the cross-section and/or manufacturing uncertainties $(\% \Delta \mathrm{k} / \mathrm{k})$.

- Top five nuclide-reaction contributors of the uncertainty in $k_{\infty}$. This will allow participants to identify reactions that contribute most to the total uncertainties. The fractional values for the five contributors must be determined $(\% \Delta \mathrm{k} / \mathrm{k})$.

- Relative power density distribution for three axial levels (top of the core, mid-core, and bottom of the core), as well as standard deviations.

- Power axial offset and standard deviation, as defined in Phase I.

- Control rod worth and standard deviation (\%).

The Excel templates for Exercises II-2a/b will be finalized at the Research Coordination Meeting (RCM) that will be held in Vienna in May 2018.

\section{Exercise II-3}

Participants are requested to provide the following parameters for comparison of Exercise II-3:

- Maximum total power (MW) reached during the reactivity insertion and standard deviation.

- Time behaviour of the core total power in 10-second intervals between 0 and 320 seconds and standard deviation of this curve.

- Top five delayed neutron fractions and lifetimes that contribute the most uncertainty in the total power. The fractional values for the five contributors must be determined $(\% \Delta \mathrm{P} / \mathrm{P})$.

- Relative power density distribution for three axial levels (top of the core, mid-core, and bottom of the core), as well as standard deviations at four time points: $0,80,160$, and 240 seconds.

- Power axial offset and standard deviation at four time points: 0, 80, 160, and 240 seconds.

The Excel template for Exercise II-3 will be finalized at the RCM that will be held in Vienna in May 2018. 


\section{Exercise II-4}

Participants are requested to provide the following parameters for comparison of Exercise II-4:

- Maximum fuel, moderator and reflector temperature (K), and standard deviations. The locations of these parameters must also be reported.

- Core-averaged fuel and moderator temperature (K) and standard deviations.

- Total core bypass flow $(\mathrm{kg} / \mathrm{s})$ and standard deviation.

- Fuel temperature distribution for three axial levels (top of the core, mid-core, and bottom of the core), as well as standard deviations.

The Excel template for Exercise II-4 will be finalized at the RCM that will be held in Vienna in May 2018. 


\section{Appendix C}

\section{Fuel and Graphite Thermo-Physical Properties}




\section{Appendix C}

\section{Fuel and Graphite Thermo-Physical Properties}

The complex dependence of graphite thermal conductivity on temperature and fluence requires specific attention. The same correlations prescribed for the Organisation for Economic Cooperation and Development/Nuclear Energy Agency Modular High-Temperature Gas-Cooled Reactor-350 benchmark [1] are used in this Coordinated Research Project on high-temperature gas-cooled reactor uncertainty analysis in modeling specification for use in the Phase II exercises. A summary of these correlations are presented here for all fuel, graphite, and metallic materials.

\section{C-1. GRADE H-451 GRAPHITE}

For this benchmark, all material thermodynamic properties are assumed isotropic. Table $\mathrm{C}-1$ and Figure $\mathrm{C}-1$ show that considerable thermal conductivity dependence exists on the fluence level, varying by almost $300 \%$ at $1,000 \mathrm{~K}$ between 0 and $8 \times 10^{25} \mathrm{n} / \mathrm{m}^{2}$. If implemented as a statistical uncertainty in this uncertainty analysis in modeling specification, this parameter will therefore dominate all other uncertainties (specifically in the transient cases). The variation in fluence is a function of the operational history of the reactor and, as such, will exhibit spatial and temporal variations. For the Phase II specifications, a constant fluence point closest to the preferred range of the AGR-1 Fuel Irradiation Program [2] was chosen $\left(3 \times 10^{25} \mathrm{n} / \mathrm{m}^{2}\right)$ to represent the "expected" or best-estimate value of the H-451 graphite thermal conductivity.

Table C-1. Thermo-physical properties of Grade H-451 graphite.

$\left.\begin{array}{|l|c|}\hline \multicolumn{1}{|c|}{\text { Parameter }} & \text { Value }^{\mathrm{a}} \\ \hline \begin{array}{l}\text { Thermal conductivity } \\ (\mathrm{W} / \mathrm{m} / \mathrm{K})\end{array} & k=4.19346 \times 10^{-6} T^{2}-2.13523 \times 10^{-2} T+5.41993 \times 10^{1} \\ \hline \text { Density }\left(\mathrm{kg} / \mathrm{m}^{3}\right) & C_{p}=\left(\begin{array}{l}0.54212-2.42667 \times 10^{-6} T-90.2725 T^{-1}-43449.3 T^{-2} \\ +1.59309 \times 10^{7} T^{-3}-1.43688 \times 10^{9} T^{-4}\end{array}\right) \cdot 4184 \\ \hline \text { Specific heat }(\mathrm{J} / \mathrm{kg} . \mathrm{K}) & 0.85\end{array}\right)$.




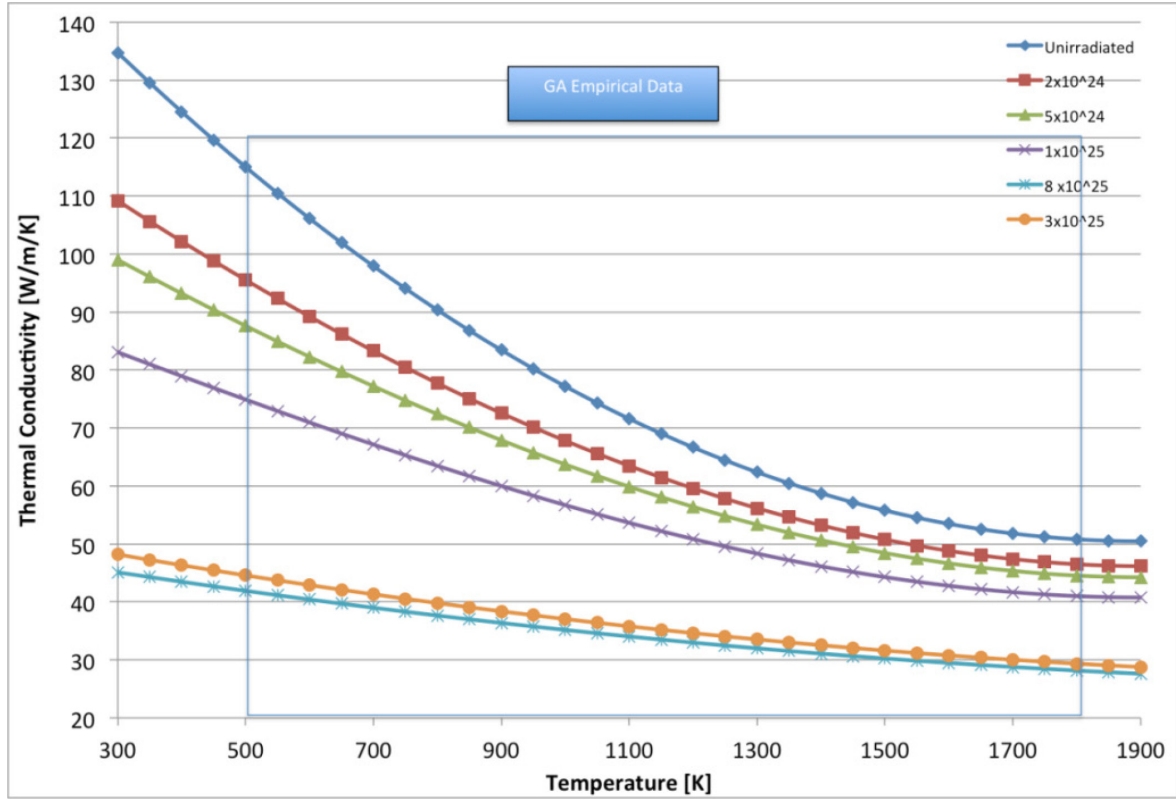

Figure C-1. Thermal conductivity of Grade H-451 graphite.

\section{C-2. PYROLITIC CARBON LAYER}

The tristructural isotropic (TRISO) particles include an outer and inner pyrolitic carbon (PyC) layer that surrounds the silicon carbide ( $\mathrm{SiC}$ ) layer and provide structural support. A porous carbon layer is positioned between the kernel and the inner PyC to retain fission gases (also called the "buffer layer"). The thermo-physical properties of the $\mathrm{PyC}$ and porous carbon layers are included in Table C-2.

Table C-2. Pyrolitic and porous carbon thermo-physical properties.

\begin{tabular}{|c|c|c|c|}
\hline \multirow{2}{*}{\begin{tabular}{l}
\multicolumn{1}{c}{ Property } \\
Thermal conductivity \\
$(\mathrm{W} / \mathrm{m} / \mathrm{K})$
\end{tabular}} & \multicolumn{3}{|c|}{ Value } \\
\hline & & $\begin{array}{l}k_{P y C}=244.3 T^{-0.574}\left[1-0.3662\left(1-e^{-1.005 \Gamma}\right)-0.03554 \Gamma\right] \\
{\left[\frac{\rho_{P y C}}{2.2\left(1930-\rho_{P y C}\right)+\rho_{P y C}}\right]} \\
k_{P C}=122.15 T^{-0.574}\left[1-0.3662\left(1-e^{-1.005 \Gamma}\right)-0.03554 \Gamma\right] \\
{\left[\frac{\rho_{P C}}{2.2\left(1930-\rho_{P C}\right)+\rho_{P C}}\right]} \\
\Gamma=\text { neutron fluence }=3 \times 10^{25} \mathrm{n} / \mathrm{m}^{2}\end{array}$ & \\
\hline Density PyC $\left(\mathrm{kg} / \mathrm{m}^{3}\right)$ & & 1,900 & \\
\hline Density porous $\mathrm{C}\left(\mathrm{kg} / \mathrm{m}^{3}\right)$ & & 1,050 & \\
\hline Specific heat $(\mathrm{J} / \mathrm{kg} / \mathrm{K})$ & $C_{p}=$ & $\left(\begin{array}{l}0.54212-2.42667 \times 10^{-6} T-90.2725 T^{-1}-43449.3 T^{-2} \\
+1.59309 \times 10^{7} T^{-3}-1.43688 \times 10^{9} T^{-4}\end{array}\right)$ & $\cdot 4184$ \\
\hline
\end{tabular}




\section{C-3. FUEL COMPACT MATRIX GRAPHITE}

The fuel compact consists of a large number of TRISO-coated particles embedded in a graphite matrix. The thermo-physical properties for the graphite matrix material are included Table C-3.

Table C-3. Compact matrix graphite thermo-physical properties.

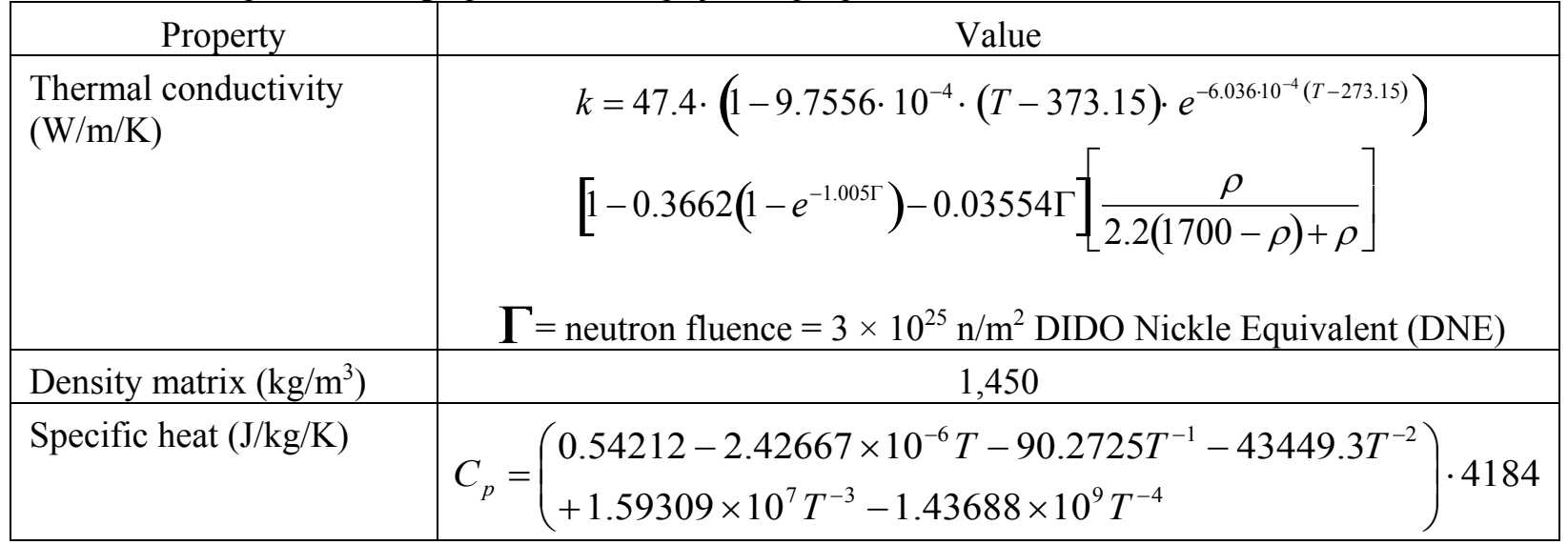

\section{C-4. SiC LAYER}

The thermo-physical properties for the SiC layer are shown in Table C-4.

Table C-4. SiC thermo-physical properties.

\begin{tabular}{|l|c|}
\hline \multicolumn{1}{|c|}{ Property } & Value \\
\hline Thermal conductivity $(\mathrm{W} / \mathrm{m} / \mathrm{K})$ & $k=\left(\frac{17885}{T}+2\right) e^{-0.1277 \Gamma}$ \\
& $\Gamma=$ neutron fluence $=3 \times 10^{25} \mathrm{n} / \mathrm{m}^{2} \mathrm{DNE}$ \\
\hline Density $\left(\mathrm{kg} / \mathrm{m}^{3}\right)$ & 3,190 \\
\hline Specific heat $(\mathrm{J} / \mathrm{kg} / \mathrm{K})$ & $C_{p}=925.65+0.3772 T-7.9259 \times 10^{-5} T^{2}-\frac{3.1946 \times 10^{7}}{T^{2}}$ \\
\hline
\end{tabular}

\section{C-5. UC . $_{0.5} \mathrm{O}_{1.5}$ KERNEL}

Since no data is available for $\mathrm{UC}_{0.5} \mathrm{O}_{1.5}$, uranium dioxide $\left(\mathrm{UO}_{2}\right)$ properties will be used instead. 


\section{C-5.1 Thermal Conductivity of $\mathrm{UO}_{2}$}

The model for irradiated $\mathrm{UO}_{2}$ thermal conductivity is specified below:

$k(T, B, p)=k_{0}(T)^{*} F D^{*} F P^{*} F R[\mathrm{~W} / \mathrm{m} . \mathrm{K}]$

where

$$
\begin{aligned}
& \mathrm{T}=\text { temperature }[\mathrm{K}] \\
& \mathrm{B}=\text { burnup [at. \%] } \\
& \mathrm{p}=\text { porosity of } \mathrm{UO}_{2} \text { [unit less] } \\
& \rho=\text { density of } \mathrm{UO}_{2}\left[\mathrm{~kg} / \mathrm{m}^{3}\right] \\
& \rho_{\mathrm{TD}}=\text { theoretical density of } \mathrm{UO}_{2}\left[\mathrm{~kg} / \mathrm{m}^{3}\right] \\
& \mathrm{k}_{\mathrm{o}}=\text { conductivity of } 100 \% \text { dense } \mathrm{UO}_{2}[\mathrm{~W} / \mathrm{m} / \mathrm{K}] \\
& \mathrm{FD}=\text { dissolved solid fission product factor [unit less] } \\
& \mathrm{FP}=\text { precipitated solid fission product factor [unit less] } \\
& \mathrm{FR}=\text { radiation damage factor [unit less] } \\
& p=\frac{\rho_{T D}-\rho}{\rho_{T D}}=0 \\
& t=\frac{T(K)}{1000} \\
& k_{0}(T)=\frac{115.8}{7.5408+17.692 t+3.6142 t^{2}}+7410.5 t^{-5 / 2} e^{-16.35 / t} \\
& F D=\left(\frac{1.09}{B^{3.265}}+0.0643 \sqrt{\frac{T}{B}}\right) \arctan \left[\left(\frac{1.09}{B^{3.265}}+0.0643 \sqrt{\frac{T}{B}}\right)^{-1}\right\rfloor \\
& F P=1+\frac{0.019 B}{3-0.019 B}\left[1+e^{-(T-1200) / 100}\right]^{-1} \\
& F R=1-\frac{0.2}{1+e^{(T-900) / 80}}
\end{aligned}
$$




\section{C-5.2 Heat Capacity of $\mathrm{UO}_{2}$}

The specific heat capacity model covers the temperature range $298.15 \mathrm{~K} \leq \mathrm{T}<3120 \mathrm{~K}$, and it is functionalized as:

$$
C_{p}(T)=302.27\left(\frac{548.68}{T}\right)^{2} \frac{e^{548.68 / T}}{\left(e^{548.68 / T}-1\right)^{2}}+2 * C_{2}(B) T+8.741 \times 10^{7} * 18531.7 \frac{e^{-18,531.7 / T}}{T^{2}}
$$

where

$$
\begin{aligned}
& \mathrm{C}_{\mathrm{p}}(\mathrm{T})=\text { specific heat capacity }[\mathrm{J} / \mathrm{kg} \cdot \mathrm{K}] \\
& \mathrm{T}=\text { temperature }[\mathrm{K}] \\
& C_{2}(B)=8.463 \times 10^{-03}(1+0.011 * B)[\text { at. } \% \text { ] } \\
& \mathrm{B}=\text { burnup [at. \%]. }
\end{aligned}
$$

\section{C-5.3 Density of $\mathrm{UO}_{2}$}

Participants should use the fixed value $\rho=10,400 \mathrm{~kg} / \mathrm{m}^{3}$. Dimensional changes in the kernel density with temperature are not taken into account.

\section{C-6. EFFECTIVE PROPERTIES FOR TRISO PARTICLES}

The effective thermal conductivity of the TRISO particles is computed with:

$k_{\text {eff }, T R I S O}=k_{m}\left(\frac{1-2 B_{\left(N_{\text {coat }}+2\right)}}{1+B_{\left(N_{\text {coat }}+2\right)}}\right)$

where

$$
\begin{aligned}
k_{m}= & \text { conductivity of the graphite matrix } \\
B_{\left(N_{\text {coat }}+2\right)=} & \text { coefficient obtained from inverting the matrix system that represents the various } \\
& \text { TRISO coatings as developed by AMEC/NSS [3]. }
\end{aligned}
$$

The actual matrix shown in [3] is in error. The correct matrix is given in Figure C-2 for four coatings $\left(\mathrm{N}_{\text {coat }}=4\right)$. 


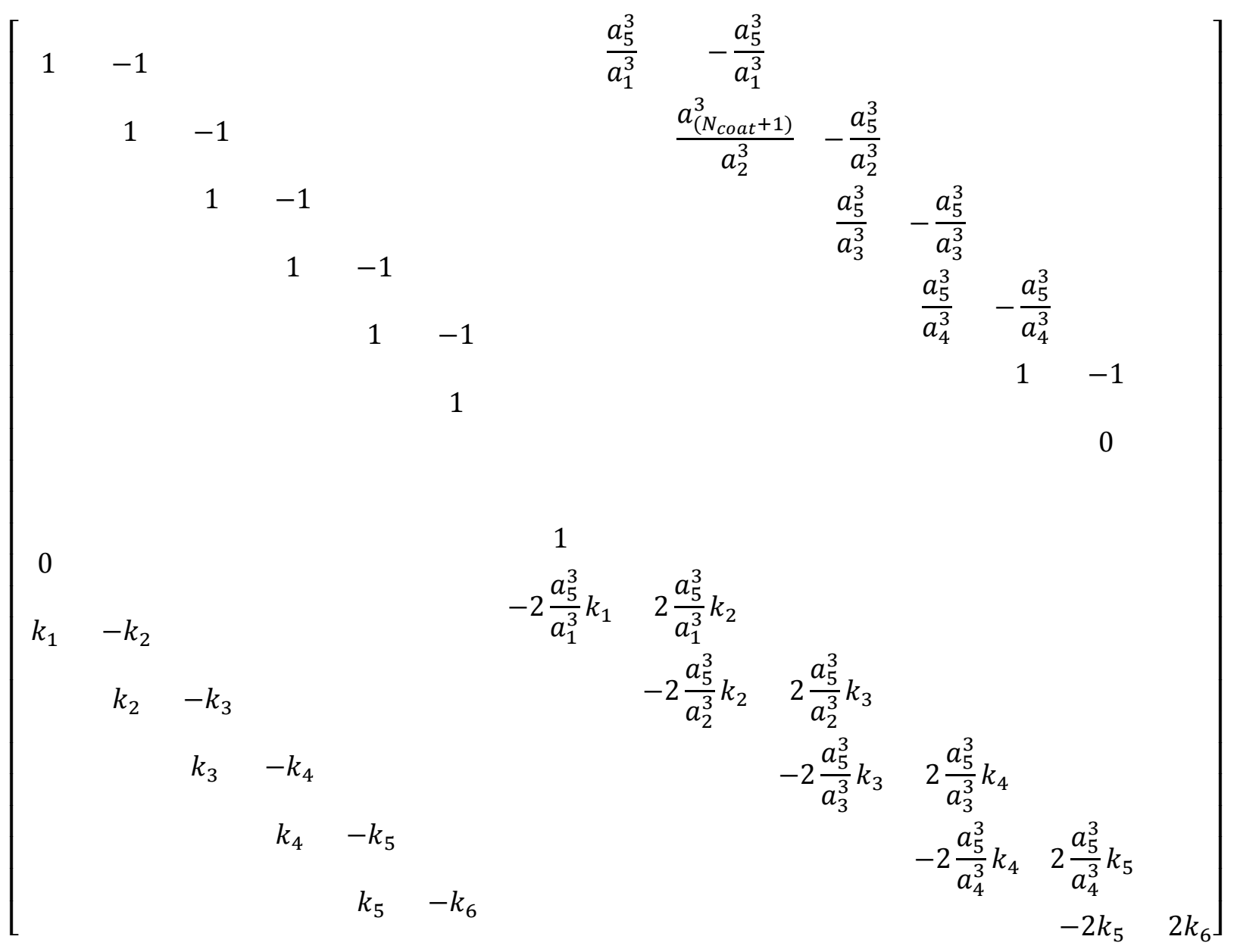

Figure C-2. Corrected matrix for the AMEC compact model.

The effective specific heat capacity is computed with a scheme based on balance of energy and the effective density with a scheme based on balance of mass:

$C p_{\text {eff }}=\frac{\int \rho C p d V}{\int \rho d V} \rho_{\text {eff }}=\frac{\int \rho d V}{\int d V}$

\section{C-7. EFFECTIVE PROPERTIES FOR FUEL COMPACTS}

The thermal conductivity of fuel compacts is computed with:

$k_{\text {eff,compact }}=k_{m}\left(\frac{1-2 \alpha B_{\left(N_{\text {coat }}+2\right)}}{1+\alpha B_{\left(N_{\text {coat }}+2\right)}}\right)$

Where

$$
\begin{array}{ll}
k_{m} & =\text { conductivity of the graphite matrix } \\
\alpha & =\text { volume fraction occupied by the TRISO particles } \\
B_{\left(N_{\text {coat }}+2\right)}= & \text { coefficient obtained from inverting the matrix system that represents the various } \\
& \text { TRISO coatings [3]. }
\end{array}
$$

The effective specific heat capacity is computed with a scheme based on balance of energy and the effective density with a scheme based on balance of mass, as shown above. 


\section{C-8. EFFECTIVE PROPERTIES FOR THERMAL UNIT CELLS}

The thermal conductivity model of the thermal unit cell is based on Maxwell's theory of the conductivity of composite materials. The original theory is derived for two materials, but it is extended to three materials for the high-temperature gas-cooled reactor applications by AMEC/NSS [3]. The effective radial conductivity of a thermal unit cell is given by the following expression:

$$
k_{\text {eff }}=k_{s}\left\{1-\frac{2\left[\alpha_{1}\left(k_{s}-k_{p o r}\right)\left(k_{s}+k_{F C}\right)+\alpha_{2}\left(k_{s}-k_{F C}\right)\left(k_{s}+k_{p o r}\right)\right]}{\left[\left(k_{s}+k_{p o r}\right)\left(k_{s}+k_{F C}\right)+\alpha_{1}\left(k_{s}-k_{p o r}\right)\left(k_{s}+k_{p o r}\right)+\alpha_{2}\left(k_{s}-k_{F C}\right)\left(k_{s}+k_{p o r}\right)\right]}\right\}
$$

where

$\mathrm{k}_{\text {eff }}=$ effective radial thermal conductivity of the cell

$\mathrm{k}_{\mathrm{s}}=$ thermal conductivity of the graphite

$\mathrm{k}_{\mathrm{por}}=$ thermal conductivity of the matrix material

$\mathrm{k}_{\mathrm{FC}}=$ thermal conductivity of the fuel compact

$\alpha_{1}=$ volume fraction of gap material

$\alpha_{2}=$ volume fraction of fuel compacts.

The effective axial conductivity of a thermal unit cell is given with the following expression:

$k_{\text {eff,axial }}=k_{s} \alpha_{3}+k_{F C} \alpha_{2}+k_{\text {por }} \alpha_{1}$

where $\alpha_{3}=$ volume fraction of graphite.

The effective specific heat capacity is computed with a scheme based on balance of energy and the effective density with a scheme based on balance of mass:

$C p_{\text {eff }}=\frac{\int \rho C p d V}{\int \rho d V} \rho_{\text {eff }}=\frac{\int \rho d V}{\int d V}$ 


\section{REFERENCES}

1. Ortensi, J., et al. "Benchmark of the Modular High-Temperature Gas-Cooled Reactor 350 MW Core Design," Volumes I and II, NEA/NSC/R(2017)4, February 2018.

2. Maki, J. T., AGR-1 Irradiation Experiment Test Plan, INL/EXT-05-00593, Idaho National Laboratory, Rev. 3, 2009.

3. Stainsby, R., et al., Investigation of Local Heat Transfer Phenomena in a Prismatic Modular Reactor Core, NR001/RP/001 R1, AMEC NSS Limited, 2009. 
Appendix D

\section{Manufacturer and Material Uncertainty Data for Phase II}




\section{Appendix D}

\section{Manufacturer and Material Uncertainty Data for Phase II}

In addition to cross-section uncertainties, various data sources have been used to compile a set of uncertainties related to manufacturer data, material properties, and boundary conditions. The inclusion of these types of uncertainties is optional for Coordinated Research Project participants that will only provide data for the neutronics exercises, since the main focus is the cross-section uncertainty effect. Participants should indicate which of these uncertainties they included in their combined analyses if the full set was not used. The manufacturer and material uncertainty data related to the Phase I exercises were provided in Appendix C of the Phase I specifications [4]. Since some of these uncertainties only applied to the lattice models (e.g., tristructural isotropic [TRISO] and fuel compact geometries), participants are requested to indicate the method used to propagate these uncertainties into the Phase II core models. The manufacturer data and material properties that are applicable to the core models are detailed here.

The nominal (i.e., best estimate, expected, or mean) and one standard deviation values for the neutronic number densities that must be used for Exercises II-1, II-2, and II-4 are included in Table D-1. The nominal and one standard deviation thermal fluid values to be used as input for Exercises II-3 and II-4 are included in Table D-2. The statistical distribution types are Gaussian, unless otherwise indicated.

Table D-1. Number densities for Exercises II-1, II-2 and II-4-nominal and $1 \sigma$ uncertainties values.

\begin{tabular}{|l|c|c|c|c|}
\hline \multicolumn{1}{|c|}{ Number Densities } & Nuclide & $\begin{array}{c}\text { Nominal/Mean Value } \\
(\mathrm{at} / \mathrm{b}-\mathrm{cm})\end{array}$ & $\begin{array}{c}1 \sigma \text { Standard Deviation } \\
\text { Uncertainty }\end{array}$ & Source \\
\hline Compact matrix & Graphite & $7.2701 \mathrm{E}-02$ & $\pm 0.63 \%$ & {$[1]$} \\
\hline Coolant channels & ${ }^{4} \mathrm{He}$ & $2.4600 \mathrm{E}-05$ & None & - \\
\hline H-451 block graphite ${ }^{\mathrm{a}}$ & Graphite & $9.2756 \mathrm{E}-02$ & $\pm 0.06 \%$ & {$[2]$} \\
\hline $\begin{array}{l}\text { a. } \\
\text { The information of the H-451 block graphite can be applied to the block graphite in the unit cell and fuel } \\
\text { blocks, as well as to the reflector block in the super cell. }\end{array}$
\end{tabular}


Table D-2. Exercises II-4input parameters-nominal and $1 \sigma$ uncertainties values.

\begin{tabular}{|c|c|c|c|}
\hline Input Parameter & $\begin{array}{l}\text { Nominal/Mean } \\
\text { Value }\end{array}$ & $\begin{array}{l}1 \sigma \text { Standard } \\
\text { Deviation } \\
\text { Uncertainty }\end{array}$ & Source \\
\hline \multicolumn{4}{|c|}{ Boundary Conditions } \\
\hline Fuel compact power density & $26 \mathrm{MW} / \mathrm{m}^{3}$ & $\pm 2.5 \%$ & Total power uncertainty from [3] \\
\hline Heat transfer coefficient & $1,700 \mathrm{~W} / \mathrm{m}^{2} . \mathrm{K}$ & $\pm 2.5 \%$ & $\begin{array}{l}\text { Helium conductivity and specific heat } \\
\text { uncertainty from [3]; friction and pipe } \\
\text { correlation uncertainty assumed at } \\
\text { similar magnitude - to be confirmed }\end{array}$ \\
\hline TRISO packing fraction & 0.35 & None & $\begin{array}{l}\text { Use to assign compact power density } \\
\text { to TRISOs. }\end{array}$ \\
\hline Fuel compact/graphite gap width & $0.125 \mathrm{~mm}$ & $\pm 1 \%$ & Assumed- to be confirmed \\
\hline \multicolumn{4}{|c|}{ Material Properties $^{\mathbf{a}}$} \\
\hline Thermal conductivities & $\begin{array}{l}\text { Correlations } \\
\text { specified in } \\
\text { Appendix C for } \\
\text { each material }\end{array}$ & $\pm 7 \%$ & [3] \\
\hline Specific heat (includes density as $\rho c_{p}$ ) & $\begin{array}{l}\text { Correlations } \\
\text { specified in } \\
\text { Appendix C for } \\
\text { each material }\end{array}$ & $\pm 3 \%$ & [3] \\
\hline Emissivity & 0.85 & $\pm 3.5 \%$ & {$[3]$} \\
\hline Compact matrix density $\left(\mathrm{kg} / \mathrm{m}^{3}\right)$ & 1,450 & $\pm 0.63 \%$ & [4] \\
\hline $\mathrm{H}-451$ block graphite density $\left(\mathrm{kg} / \mathrm{m}^{3}\right)$ & 1,850 & $\pm 0.06 \%$ & {$[2]$} \\
\hline \multicolumn{4}{|c|}{ Coated TRISO Particles Properties } \\
\hline $\mathrm{UC}_{0.5} \mathrm{O}_{1.5}$ kernel diameter $(\mu \mathrm{m})$ & 425 & $\pm 2.58 \%$ & [1] \\
\hline Buffer thickness $(\mu \mathrm{m})$ & 100 & $\pm 7.93 \%$ & [1] \\
\hline $\begin{array}{l}\text { Inner pyrolitic carbon (IPyC) } \\
\text { thickness }(\mu \mathrm{m})\end{array}$ & 40 & $\pm 5.84 \%$ & [1] \\
\hline Silicon carbide $(\mathrm{SiC})$ thickness $(\mu \mathrm{m})$ & 35 & $\pm 3.69 \%$ & {$[1]$} \\
\hline $\begin{array}{l}\text { Outer pyrolytic carbon }(\mathrm{OPyC}) \\
\text { thickness }(\mu \mathrm{m})\end{array}$ & 40 & $\pm 5.13 \%$ & [1] \\
\hline $\mathrm{UC}_{0.5} \mathrm{O}_{1.5}$ kernel density $\left(\mathrm{kg} / \mathrm{m}^{3}\right)$ & 10,400 & $\pm 0.14 \%$ & [1] \\
\hline Buffer density $\left(\mathrm{kg} / \mathrm{m}^{3}\right)$ & 1,050 & $\pm 3.64 \%$ & [1] \\
\hline IPyC density $\left(\mathrm{kg} / \mathrm{m}^{3}\right)$ & 1,900 & $\pm 0.74 \%$ & [1] \\
\hline $\mathrm{SiC}$ density $\left(\mathrm{kg} / \mathrm{m}^{3}\right)$ & 3,190 & $\pm 0.10 \%$ & [1] \\
\hline OPyC density $\left(\mathrm{kg} / \mathrm{m}^{3}\right)$ & 1,900 & $\pm 0.42 \%$ & [1] \\
\hline
\end{tabular}




\section{REFERENCES}

1. Maki, J. T., AGR-1 Irradiation Experiment Test Plan, INL/EXT-05-00593, Idaho National Laboratory, Rev. 3, 2009.

2. NEA, Temperature Effect on Reactivity in VHTRC 1 Core, VHTRC GCR EXP 001, CRIT COEF, NEA/NSC/DOC(2006)2, 2006.

3. Strydom, G., "TINTE Uncertainty Analysis of the Maximum Fuel Temperature during a DLOFC Event for the 400 MW Pebble Bed Modular Reactor," Proceedings of ICAPP 2004, Pittsburgh, PA, U.S.A., 2004.

4. Collin, B. P. and P. W. Humrickhouse, PLN-3867, "AGR-3/4 Irradiation Experiment Test Plan," Idaho National Laboratory, Rev. 0, October 2011. 